\title{
Doxorubicin Hydrochloride-Loaded Nonionic Surfactant Vesicles to Treat Metastatic and Non-Metastatic Breast Cancer
}

\author{
Martina Di Francesco, $\square$ Christian Celia, $\square$ Maria Chiara Cristiano, Nicola d'Avanzo, Barbara Ruozi, \\ Constantin Mircioiu, Donato Cosco, Luisa Di Marzio,* and Massimo Fresta*
}

Cite This: ACS Omega 2021, 6, 2973-2989

Read Online

ABSTRACT: Doxorubicin hydrochloride (DOX) is currently used to treat orthotropic and metastatic breast cancer. Because of its side effects, the use of DOX in cancer patients is sometimes limited; for this reason, several scientists tried designing drug delivery systems which can improve drug therapeutic efficacy and decrease its side effects. In this study, we designed, prepared, and physiochemically characterized nonionic surfactant vesicles (NSVs) which are obtained by selfassembling different combinations of hydrophilic (Tween 20) and hydrophobic (Span 20) surfactants, with cholesterol. DOX was loaded in NSVs using a passive and $\mathrm{pH}$ gradient remote loading procedure, which increased drug loading from $\sim 1$ to $\sim 45 \%$. NSVs were analyzed in terms of size, shape, size distribution, zeta potential, long-term stability, entrapment efficiency, and release kinetics, and nanocarriers having the best physiochemical parameters were selected for further in vitro tests. NSVs with and without DOX were stable and showed a sustained drug

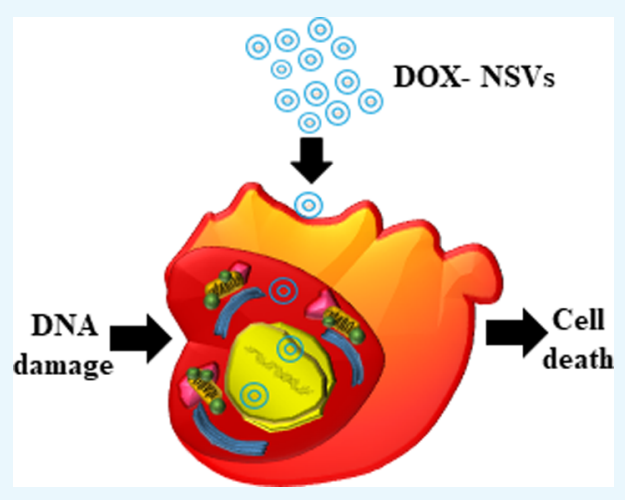
release up to $72 \mathrm{~h}$. In vitro studies, with MCF-7 and MDA MB 468 cells, demonstrated that NSVs, containing Span 20, were better internalized in MCF-7 and MDA MB 468 cells than NSVs with Tween 20. NSVs increased the anticancer effect of DOX in MCF-7 and MDA MB 468 cells, and this effect is time and dose dependent. In vitro studies using metastatic and nonmetastatic breast cancer cells also demonstrated that NSVs, containing Span 20, had higher cytotoxicity than NSVs with Tween 20 . The resulting data suggested that DOX-loaded NSVs could be a promising nanocarrier for the potential treatment of metastatic breast cancer.

\section{INTRODUCTION}

Cancer is one of the principal causes of death in the world. Breast cancer has a high incidence and frequency and represents the second leading cause of cancer deaths in the female population worldwide, with an estimated 2.1 million new cases and 626,679 deaths reported in 2018. ${ }^{1}$ It shows a higher incidence rate in high-income countries than in lowincome and middle-income countries. ${ }^{2}$ Nowadays, there are more than 3.5 million breast cancer survivors, which include women still being treated and those who have completed treatment. ${ }^{2}$ Breast cancer has been considered for a long time as the most aggressive cancer form affecting worldwide populations, particularly female, with an increased incidence and high mortality. ${ }^{3}$ Early-stage breast cancer is treated using surgery, which is often combined with radio- and chemotherapies to decrease the risk of recurrence; while metastasis are treated early by systemically injecting drugs, such as chemotherapeutics, targeted molecules, hormones, and, recently, immune modulators. ${ }^{4}$

Conventional therapies, such as surgery, radiotherapy, chemotherapy, and modern treatments, including immunotherapy, biological and differentiating drugs, anti-angionic compounds, signal transduction inhibitors, vaccines, targeted therapy, hormonal therapy, and gene therapy, showed a lack of efficacy for treating cancer and its resistance, as well as side effects, which occur quickly after several and multiple administrations because of scheduled protocols. ${ }^{3,5}$

Anthracyclines, such as doxorubicin and epirubicin, taxanes, including paclitaxel and docetaxel, along with fluorouracil and cyclophosphamide, are the current therapeutic options used as the combination adjuvant for breast cancer treatment. The therapeutic protocol for breast cancer treatment in the United States includes 4 cycles of doxorubicin and cyclophosphamide plus 4 cycles of paclitaxel (AC-T). ${ }^{6}$ Currently, clinical trials demonstrated that combination therapies, that is, immunotherapy, chemotherapy, and targeted therapies, can improve survival in breast cancer patients.

Physicochemical and biological properties of these chemotherapeutic drugs, for example, poor water solubility and

Received: November 3, 2020

Accepted: December 8, 2020

Published: January 22, 2021 
pharmacokinetic, chemical, and biological instability, local and systemic toxicity, can cause from moderate to severe side effects for healthy tissues because of their lack of specificity and selectivity, thus limiting the use of chemotherapeutic drugs in anticancer therapy. Moreover, conventional chemotherapeutic drugs develop resistance phenomena after multiple injections; in fact, cancer cells overexpress drug efflux pumps, which lack the responsiveness to chemotherapy under treatment. ${ }^{8,9}$

Nanomedicine offers some advantages to overcome these limitations, and particularly, it increases the efficacy of therapeutic drug dosage and decreases local and systemic side effects. ${ }^{5}$ Today, several nanomedicines are present on the market or approved for clinical trials. ${ }^{10}$ In particular, US Food and Drug Administration (FDA) approved 50 nanomedicine drugs in 2016 for clinical use in breast, like other cancer therapy. ${ }^{11}$ These nanomedicines are nanoformulations of commercially available drugs, whose clinical use, per se, is limited by their toxicity instead of reduced efficacy. ${ }^{12}$ In June 2020, 75 clinical trials, including "nano" for cancer diseases are listed as "recruiting" or "active" on ClinicalTrials.gov, and different drug delivery systems are used for anticancer therapy.

Liposomes, niosomes, polymeric microparticles, and nanoparticles have suitable physicochemical and biopharmaceutical properties to specifically target pathological tissues and control the release of payloads. ${ }^{12}$ Liposomes and niosomes, like other nanocarriers, protect drugs from enzyme inhibition, metabolism, degradation, clearance, and uptake from the reticuloendothelial system (RES) of macrophages. ${ }^{13,14}$ Furthermore, they can codeliver multiple drugs and/or diagnostic agents (e.g., contrast agents), thus making multidrug nanocarriers have theragnostic properties. ${ }^{8}$

The first generation of nanomedicine was liposomes, or Bangham's vesicles. ${ }^{15}$ Liposomes were approved for nanomedicine because they are versatile, biocompatible, and do not provide any immunogenic reaction after systemic injection. ${ }^{16}$ Currently, many other liposomal formulations for anticancer therapy have been approved for clinical trials or are marketed. ${ }^{17,18}$ DepoCyt (liposomal cytarabine), DaunoXome (liposomal daunorubicin), Myocet (liposomal doxorubicin, approved in Europe and Canada), Doxil/Caelyx (liposomal doxorubicin), Sarcodoxome (liposomal doxorubicin), Marqibo (liposomal vincristine), and Lipusu (liposomal paclitaxel, approved in China) $)^{17,18}$ are currently liposomal formulations, approved as nanomedicine, for anticancer therapy. Doxil was the first anticancer liposomal formulation approved in the early 1990s (Ben Venue Laboratories, Inc Bedford, OH) by the US FDA for the treatment of chemotherapy refractory acquired immune deficiency syndrome (AIDS)-related Kaposi's sarcoma, ${ }^{19}$ as well as breast cancer. ${ }^{20}$ The encapsulation of doxorubicin hydrochloride (DOX) inside liposomes increases drug shelf-life, distribution in tumor tissues, anticancer efficacy, and decreases side effects like cardiotoxicity, which is caused by free DOX. ${ }^{19,21}$ PEGylation of liposomes decreases the adsorption of plasmatic opsonins onto the liposomal surface and RES macrophage uptake, thus increasing long-circulation and liposomal shelf-life by hours or days after systemic injection. $^{22}$ Polyethylene glycol (PEG), coating liposomes, forms a dense and compact surface hydrophilic barrier, which hampered the adsorption of opsonins and prevented the macrophage uptake. Moreover, PEG increases vascular permeability, thus facilitating liposome accumulation and drug release into the tumor tissue by passive targeting. ${ }^{23}$ Synthetic PEGs increase significantly the systemic long- circulation and stealth properties of liposomes better than conventional and commercial PEGs, ${ }^{24}$ while a combination of PEGs at different molecular weights overcome nanoparticlemediated complement activation, thus having any significant effect on nanoparticle longevity in the blood and macrophage uptake. $^{25}$

PEGylation of bare nanocarriers are also provided by postinsertion of PEGylated lipid derivatives into preformed liposomes ${ }^{26}$ or coating nanocarriers with surfactants like polysorbates. ${ }^{27}$ The first approach depends on the thermodynamic properties and supramolecular arrangement of PEGlipid derivatives, which are in equilibrium with packed phospholipids of the bilayer. ${ }^{28}$ In fact, they are not completely dispersed in the lipid bilayer of liposomes, but PEG moieties are exchanged onto the liposomal surface, thus maintaining a dynamic equilibrium between the PEGylated and dePEGylated forms of liposomes. ${ }^{28}$ The second approach consists of replacing PEG with alkyl esters or the ether of surfactants, like sorbitan esters and polysorbates, which have repeated oxyethylene units, in their hydrophilic backbone structure, with biopharmaceutical properties similar to PEG. ${ }^{29}$

Sorbitan esters and polysorbates can also form nonionic surfactant vesicles (NSVs), or niosomes, which are a nanomedicine currently used for anticancer therapy. ${ }^{30}$ NSVs have physicochemical and biopharmaceutical properties similar to liposomes but provide some advantages like high chemical stability, lower toxicity, high performance for manufacture and therapeutic impact, and easy handling and storage. ${ }^{31}$ The low cost for manufacture guarantees a versatile application of NSVs and a large scale-up production by green solvents, despite being marketed for specific pharmaceutical and cosmetic applications. ${ }^{31}$ NSVs are safe and biocompatible nanocarriers made from surfactants, delivering different therapeutic agents, and they are used for anticancer, anti-viral, anti-inflammatory, anti-microbial, and protein therapies. ${ }^{31-33}$

Tweens and Spans are nonionic surfactants widely used as emulsifiers and stabilizers in pharmaceutical formulations, food, and cosmetic industries, ${ }^{34}$ and they are the main ingredients of NSVs in combination with cholesterol ( $\mathrm{Chol}) .^{31}$

The aim of this work was the synthesis and the physicochemical characterization of NSVs for the treatment of aggressive and metastatic breast cancer. ${ }^{35}$ In particular, we synthesized and physiochemically characterized NSVs made from different combinations of polysorbates, for example, Tween 20 or Tween 21, or sorbitan ester, for example, Span 20 and Chol, delivering DOX. DOX was used as a drug candidate because of the high responsiveness of aggressive and metastatic breast cancer versus this drug. In fact, preclinical and clinical trials demonstrated that DOX-loaded PEGylated liposomes are more selective and efficacious for breast cancer treatment than free DOX. ${ }^{36}$ NSVs with the best physicochemical parameters were selected to improve the loading of DOX and for further in vitro studies. It was previously reported that Doxil and free DOX have a similar therapeutic efficacy in vitro, but Doxil showed less side effects. ${ }^{37}$ Furthermore, this effect is strictly related to the drug-to-lipid ratio; in fact, in vivo toxicity of Doxil decreases with the increase of the drug-to-lipid ratio. ${ }^{38}$ Thus, a $\mathrm{pH}$ gradient and remote loading procedure was carried out to significantly increase the entrapment efficiency (EE) of DOX inside the NSVs. MDA MB 468, an aggressive and triple negative metastatic breast cancer cell (poor prognosis for patient survival), and MCF-7, an estrogen positive receptor breast cancer cell (better prognosis for patient survival), were 
used for in vitro studies and confocal laser scanning microscopy. These different cell lines show heterogeneous responses to targeted therapeutic molecules, and they can be used to predict in vivo therapeutic responsiveness of DOX. ${ }^{39}$ Our preliminary data suggested a potential use in vitro of DOX-NSVs for the treatment of malignant and aggressive breast cancer.

\section{RESULTS AND DISCUSSION}

Physicochemical Characterization of NSVs. Average sizes, size distribution, and surface properties affect biopharmaceutics and therapeutic responsiveness of colloidal nanocarriers, and particularly long-time circulation, tumor uptake, and therapeutic and side effects. ${ }^{40}$ These parameters depend on biomaterials to make nanocarriers as well as their supramolecular arrangement. ${ }^{41}$ Based on these pieces of evidence, NSVs were synthesized using safe and biocompatible materials like Chol and various combinations of nonionic surfactants at different molar ratios (Table 2, Experimental section). Tweens are nonionic surfactants that consist of fatty acid esters of sorbitans and/or sorbides with $20 \mathrm{~mol}$ of ethylene oxide (PEO) per mole of the product; in particular, the backbone structure of Tweens has 4 units of PEO for Tween 21 (Tw21) and 20 units of PEO for Tween 20 (Tw20), respectively. ${ }^{31}$ Tweens are used as additives for foods, cosmetics, and medicines because of their amphiphilic structures; $^{31}$ and PEO, which forms hydrophilic chains of surfactants and has biopharmaceutical properties similar to PEG, may decrease opsonization and clearance mediated by the RES macrophage, as well as improve the pharmacokinetics of nanocarriers. ${ }^{42}$ Chol stabilizes NSVs because it has a structural function similar to the second acyl chain of phospholipids making liposomes. ${ }^{43}$

The sonication process was used to obtain NSVs with or without $\mathrm{DOX}$, and passive and $\mathrm{pH}$ gradient remote loading procedures were used to increase the amount of the drug inside nanocarriers. ${ }^{44}$ Basically, drug loading of liposomes and niosomes was carried out by using both passive and active methods. These procedures generate a different accumulation of payloads inside the aqueous core of nanocarriers because of the passage of neutral or protonated compounds through the lipid bilayer of liposomes ${ }^{45}$ and niosomes. ${ }^{46}$ This exchange depends on the $\mathrm{pH}$ gradient through the lipid membrane, $\mathrm{p} K_{\mathrm{a}}$ $\log \mathrm{D}$, and buffer making an aqueous core of nanocarriers. ${ }^{47}$ Hydrophilic drugs, like DOX, which is loaded in the aqueous core of nanocarriers during the hydration step of thin-layer evaporation (TLE) process, sometimes have a low EE using passive loading. This result is specific for weak acid or base of drugs and depends on $\mathrm{pK}_{\mathrm{a}}$ and $\log \mathrm{D}$ of drugs. ${ }^{47}$ Conversely, the active loading using the $\mathrm{pH}$ gradient and remote loading procedures significantly increased the drugs accumulated in the aqueous core of nanocarriers because of the precipitation of payloads in a crystalline form as a consequence of the gel-like structure forming under the $\mathrm{pH}$ of the aqueous core, which is the opposite compared to the external medium. Furthermore, the EE of payloads increased by increasing the weight ratio between the payload and nanocarrier. ${ }^{48}$ The high EE of nanocarriers also plays a pivotal role in achieving a suitable drug dosage to test their in vivo activity and the related therapeutic efficacy. ${ }^{38}$

NSVs, obtained using the passive loading procedure, have average sizes from 100 to $200 \mathrm{~nm}$ (Figure S1A), which depend on the selected surfactant as well as its molar concentration; in fact, sizes increased by increasing the percentage of Tw20 and decreasing that of Tw2 1 in NSVs. ${ }^{44}$ Average sizes of empty NSVs were less affected by the nature and molar concentration of surfactants that are used as a combination in NSVs and have similar physicochemical properties (Figure S1A). This may depend on the absence of surfactants with unsaturated chains. In fact, Tw20 and Tw21 have the same saturated fatty acid, that is, lauryl acid, in their backbone structure and different for the total number of PEO units making ether bonds in the sorbitan esters. ${ }^{44}$ Only, empty NSVs, which are obtained using a single surfactant, have different average sizes (Figure S1A). These results agreed with data previously reported and depended on the different hydrophilic properties of surfactants (Span 60) making NSVs. ${ }^{49}$ Although Tw20 and Tw21 were similar to each other in the hydrophobic part, the increased units of PEO in Tw20 favored the induction of a temporary polarization of the functional groups present in the backbone structure of surfactants, and thus the relative delocalization of electronic subatomic particles in Tween derivatives. ${ }^{50}$

The passive loading of DOX did not affect the average sizes of NSVs, except for NSV5 (Figure S1A). Average sizes are similar for the resulting NSVs with and without drug, and a slight increase of average sizes occurred only for NSV1 and NSV2; conversely, average sizes increased significantly for NSV5 (from 107 to $190 \mathrm{~nm}$ ) with DOX obtained using passive loading (Figure S1A). This increase (NSV5) may depend on the presence of less electrostatic interaction between DOX and PEO units in the head group of Tw21 (Tw21, 4 vs Tw 20, 20). ${ }^{51}$

NSVs had a narrow size distribution with a polydispersity index (PDI) below 0.3 (Figure S1B). PDI demonstrates that the nanocarriers are stable, and the results agreed with the data previously reported. $^{44}$

$\zeta$-Potential of NSVs affects their stability over time; in fact, neutral particles are not stable and can aggregate during storage; moreover, $\zeta$-potential affects the interaction of nanocarriers with plasma proteins, thus altering particle surface properties and biological behavior and targeting. Moreover, the modification of surface charges in nanoparticles can cause hemolysis of erythrocytes, particularly for high positively $\zeta$ potential values. $^{52} \zeta$-Potential of NSVs is negative and has values in the range from -18 to $-40 \mathrm{mV}$ (Figure S1C). The resulting $\zeta$-potential values depend on the surfactant structure, and molar concentration as well as the payload (Figure S1C). The negative values of the $\zeta$-potential showed that the nanocarriers are stable and no aggregation phenomena occurred overtime. ${ }^{44,49}$ Anticancer activity of chemotherapeutic drugs depends on their uptake and accumulation inside cancer cells and tumor tissues, as well as the amount of payloads delivered by nanocarriers and their relative release. ${ }^{53}$

NSVs were obtained using two different methods, for example, passive and $\mathrm{pH}$ gradient remote loading procedures, which entrap hydrophilic drugs based on the physicochemical interaction of drugs with buffers of the internal core of nanocarriers. ${ }^{54}$ Buffer composition ${ }^{54}$ and preparation method $^{55}$ can significantly affect the EE of the drug in NSVs; in particular, NSVs obtained using passive loading have a DOX EE percentage below 10\% (Figure S1D). EE \% of DOX-NSVs, which are synthesized using passive loading, depends on surfactant compositions, while it is independent from the preparation procedure. The passive loading of payloads was allowed to have the highest values of DOX EE \% for NSV1. The EE \% depended on the amount of Tw20 used to make 


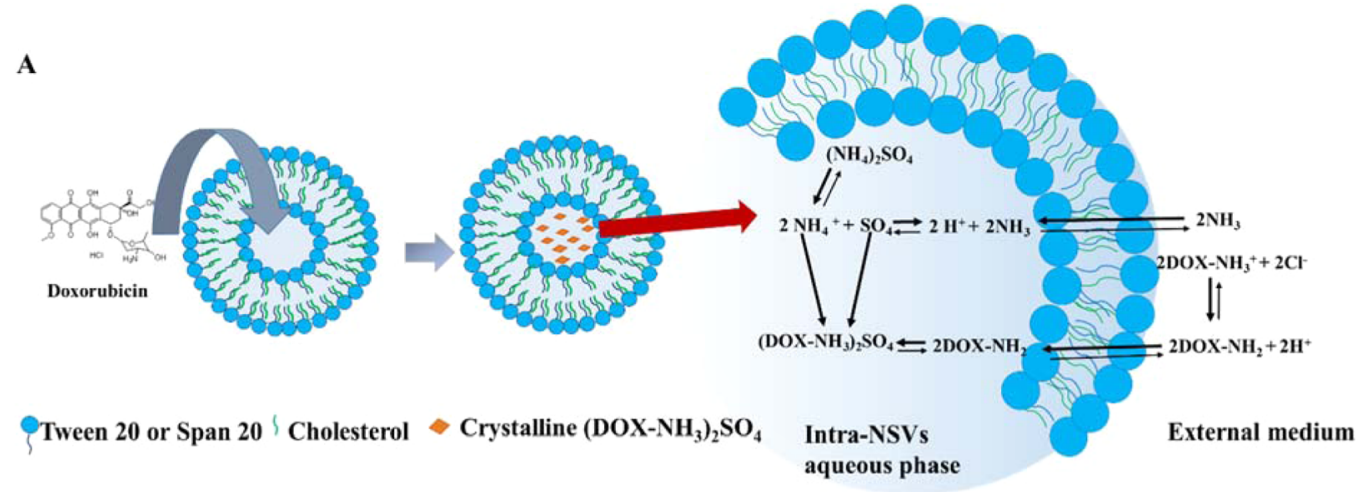

B

\begin{tabular}{ccccc}
\hline Sample & Size $(\mathbf{n m})$ & PDI $^{\mathbf{a}}$ & $\zeta$-potenzial $(\mathbf{m V})$ & EE $(\%)^{\mathbf{b}}$ \\
\hline NSV1grad & $120.6 \pm 2.07$ & $0.082 \pm 0.03$ & $-25.06 \pm 8.50$ & - \\
DOX-NSV1grad & $131.05 \pm 8.45^{*}$ & $0.25 \pm 0.08$ & $-20.0 \pm 0.11$ & $43.35 \pm 7.51$ \\
NSV6 & $128.44 \pm 0.70$ & $0.16 \pm 0.01$ & $-54.38 \pm 3.63$ & - \\
& & & & \\
DOX-NSV6grad & $129.20 \pm 0.18$ & $0.12 \pm 0.01$ & $-67.66 \pm 1.31$ & $47.93 \pm 3.94$ \\
\hline
\end{tabular}

Figure 1. Schematic representation of DOX $\mathrm{pH}$ remote loading through the niosomal membrane (A) and physicochemical characterization of empty and DOX-NSV1grad and DOX-NSV6grad (B). Statistical significance was setup at $* p<0.05$ and was calculated by comparing the average sizes of NSV1grad and DOX-NSVlgrad. Results are the average of three independent experiments \pm S.D. $(n=3)$.

NSVs, while it decreased by increasing the amount of Tw21 (Figure S1). This effect might depend on the higher number of PEO units in Tw20 than that of Tw21, which caused strong electrostatic interactions with DOX as previously reported. ${ }^{51}$ These results were in agreement with $\zeta$-potential values which decreased significantly only for NSV1 loading DOX (from -23 to $-15 \mathrm{mV}$ ), thus suggesting the presence of DOX molecules is strongly associated with the surface of NSV1 (Figure S1C). TLE guarantees the maximum EE $(\sim 10 \%)$ of NSVs using the passive loading (Figure S1D), the results are qualitatively similar to other hydrophilic drugs, like dorzolamide $\mathrm{HCl}^{46}$ brimonidine tartrate, ${ }^{56}$ and acetazolamide, ${ }^{57}$ which entrap (below $30 \%$ ) poorly hydrophilic water drugs, like DOX, in the aqueous core of nanocarriers using the conventional TLE method.

To increase the EE \% of DOX, a $\mathrm{pH}$ gradient remote loading procedure was used during the analysis. ${ }^{44,58} \mathrm{pH}$ gradient remote loading procedure were applied for NSVs having the best physicochemical and biopharmaceutical properties. In this attempt, NSV1 were selected because of its average size, size distribution, $\zeta$-potential, and stability, while NSV2 and NSV5 were excluded because average sizes increased after loading of DOX in the aqueous core of NSVs (Figure S1A). Conversely, NSV3 and NSV4 were excluded because they are obtained by combining Tw20 and Tw21 at different molar concentrations.
NSV1 that has been synthesized using the $\mathrm{pH}$ gradient remote loading procedure was reported as NSVlgrad, and it was obtained by extrusion of NSV1, as reported in the relative methods section (DOX $\mathrm{pH}$ Gradient and Remote Loading Procedure), followed by $\mathrm{pH}$ gradient remote loading procedure of DOX.

NSV1grad had average sizes of 120 and $131.05 \mathrm{~nm}$, respectively, for empty and DOX-loaded NSV1grad (Figure 1B). DOX loading NSV1grad slight increased the average sizes of nanocarriers because of the less interaction between Tw20 and DOX, as previously reported for ammonium glycyrrhizinate-loaded Tw20 niosomes. ${ }^{32}$ The results agreed with the data previously reported for NSVs made fromTw80 and Chol, which had the same molar ratio of surfactants. ${ }^{44}$ In fact, Tw80 has the same number of PEO units of Tw20 and a similar structure for the sorbitan ester derivative. The PDI of NSV1grad slightly increased by adding DOX; however, this increase is not statistically significant and PDI is below 0.3 for both empty and DOX-NSV1grad. This value of PDI showed that NSV1grad are narrow size distributed, and the drug loading did not affect its physicochemical properties.

$\zeta$-Potential values of empty and DOX-loaded NSV1grad did not change significantly and were very similar to NSV1 after the entrapment of payloads using the remote loading and $\mathrm{pH}$ gradient procedure. These results demonstrated that the 
remote loading $\mathrm{pH}$ gradient method did not modify the supramolecular structure and affect the surface properties of NSV1. Particle size and shape were also supported by transmission electron microscopy (TEM) analysis (Figure 1), which showed a spherical shape of NSV1grad with an average size of $\sim 100 \mathrm{~nm}$ and the presence of the unilamellar bilayer. The EE \% of DOX increased significantly using the $\mathrm{pH}$ gradient remote loading procedure in the NSVlgrad compared to passive loading of NSV1. The EE \% of NSV1 was $10.26 \%$ (Figure S1D) versus 44\% for NSV1grad (Figure 1B). This increase depends on different factors: (i) first, DOX is protonated and accumulated as a positively charged drug within nanocarriers; DOX precipitates in the aqueous core of the NSV1grad as crystals in the gel-like form and decreased the drug water solubility; ${ }^{54}$ (ii) second, the free base of DOX, which is not protonated can freely move through the NSV membrane until its protonation instead of the protonated drug; $^{58}$ (iii) third, the $\mathrm{pH}$ in the aqueous core of NSV1 is acidic while the external $\mathrm{pH}$ of the nanocarrier is neutral, so the free base of DOX can move through the thin-layer membrane of NSV1 by gradient drug concentration, and it is protonated inside the aqueous core of NSV1 at acidic $\mathrm{pH}$ without freely diffusing in its protonated form. ${ }^{54}$ Thus, a proton pool drives the loading of DOX inside the aqueous core of NSV1 (Figure 1A).

Passive DOX encapsulation in NSV6 was not performed because of the low EE obtained with previous formulations. In this nanocarrier, the hydrophilic surfactant, Tw20, was changed with the hydrophobic surfactant, Span 20 or Sp20. ${ }^{43}$ Sp20 is a hydrophobic surfactant which has HLB values that provide physicochemical properties similar to those of the phospholipids used for liposomes. ${ }^{59}$ Tw20 at a very small molar ratio (1\%) was added to NSV6grad to increase the longcirculation of nanocarriers and decrease RES macrophage uptake. $^{44,60}$ The presence of Tw20 in NSV6grad formulation improves stealth properties of NSVs like PEG in PEGylated liposomes. ${ }^{61}$ Moreover, 1,2-dipalmitoyl-sn-glycero-3-[phosphorac-(3-lysyl(1-glycerol))] (DPPG), a negative phospholipid, was added in NSV6grad to stabilize NSVs. In fact, the presence of negatively charged phospholipids in the bilayer of nanocarriers can prevent their aggregation and fusion, thus maintaining the shape, size, and size distribution. ${ }^{62}$ NSV6grad with or without DOX have an average size of $\sim 130 \mathrm{~nm}$, a size distribution with a PDI below 0.2 and a net negative charge with a $\zeta$-potential of $\sim-54 \mathrm{mV}$ (Figure 1B). As we previously discussed, the net negative charge of NSV6grad compared to NSV1grad depends on the presence of DPPG in the lipid layer. In particular, different $\zeta$-potential values of empty NSVs may depend on ammonium derivatives adsorbed onto their surface, which have a specific interaction with PEO of Tw20. The decrease of the $\zeta$-potential of DOX-NSV1grad may depend on the ammonium derivatives adsorbed onto the NSVgrad surface and charged DOX colocalized in the same portion of nanocarriers. $^{32}$ DOX did not affect the physicochemical properties of NSV6grad (Figure 1B). TEM analysis of NSV1grad and NSV6grad showed that NSVs have spherical shapes with a large internal aqueous space (Figure 2). The unilamellar bilayer was obtained for NSV1grad and NSV6grad, with or without DOX. The TEM images of DOX-NSV1grad and DOX-NSV6grad showed nanocarriers with dense granular structures in the aqueous core, which are similar to vincristineloaded liposomes. ${ }^{63}$ Average sizes of NSVgrad measured with TEM are similar to those previously obtained using dynamic
Empty


Figure 2. TEM images of empty and DOX-NSV1grad (top), and empty and DOX-NSV6grad (bottom). Images are representative of three independent experiments.

light scattering (DLS). DOX EE \% was 43.3\% (NSV1grad) and $47.9 \%$ (NSV6grad) for a $\mathrm{pH}$ gradient and remote loading procedure (Figure 1B). The increase in DOX EE \% with a $\mathrm{pH}$ gradient and remote loading procedure depends on the gel-like structure of the drug and its relative precipitation in the aqueous core of NSVs. The DOX-gel like structure does not freely exchange in its crystalline form through the lipid bilayer of nanocarriers and forms precipitates in the aqueous core of NSVs. This behavior changed the physical state of the drug and significantly increased DOX accumulation inside nanocarriers like for Doxil/Caelyx ${ }^{19}$ and other chemotherapeutic drugs. $^{64}$

NSV Serum Stability. Particle stability in the blood serum affects their body distribution after systemic injection. Nanocarriers interact with blood and circulating proteins, which induce mechanical stresses because of the rapid distribution, enzymatic degradation, binding to macromolecules, and macrophage uptake. ${ }^{65}$ Serum proteins adsorbed on the particle surface generate a protein corona, which increases particle sizes, size distribution, and modifies surface properties. ${ }^{66}$ The serum protein may also change osmotic equilibrium of nanocarriers thus generating internal osmotic pressure, which modifies the membrane integrity and causes the shrinkage of nanocarriers because of the water leakage from the internal particle aqueous core. ${ }^{67}$ Nanocarriers incubated with the serum slightly decreased their sizes as a consequence of shrinkage and leakage of internal water ${ }^{68}$ (Figure 3A,B). Serum proteins did not affect the average size of the NSV1grad, with or without DOX, at short incubation times and up to $8 \mathrm{~h}$ (Figure 3A); in fact, the particle sizes increased slightly only from 125 to $150 \mathrm{~nm}$, due to the presence of PEO units in NSV1grad. The results are independent on DOX loading, while PEO, similar to PEG of liposomes or other nanoparticles, generates a steric barrier hampering the serum protein adsorption on the surface of nanocarriers. ${ }^{69,70}$ Similar results were previously reported for other NSVs incubated with $45 \%$ of the fetal bovine serum (FBS). ${ }^{71}$ The average sizes of NSV1, with or without DOX, increased after $8 \mathrm{~h}$ of incubation 
A

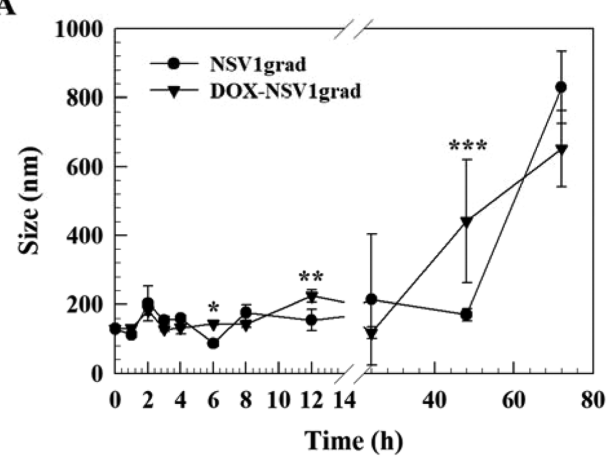

B

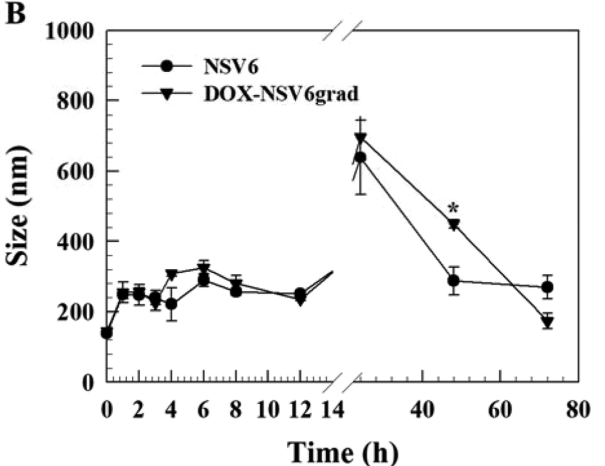

Figure 3. Serum stability of NSV1grad (A) and NSV6grad (B). Results are the average of three independent experiments \pm S.D. $(n=3)$. The $p$ values of $<0.05(*),<0.01(* *)$, and $<0.001(* * *)$, with respect to other DOX-NSVs.

A

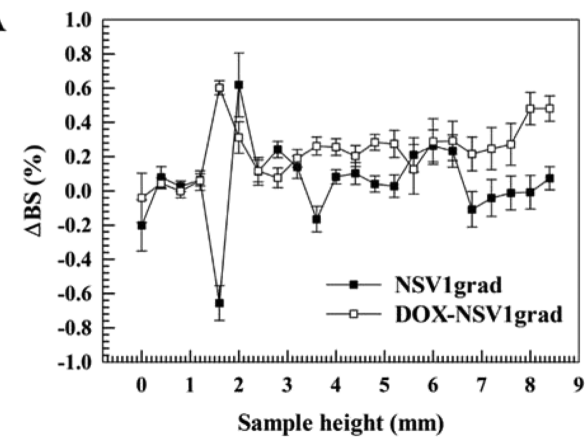

B

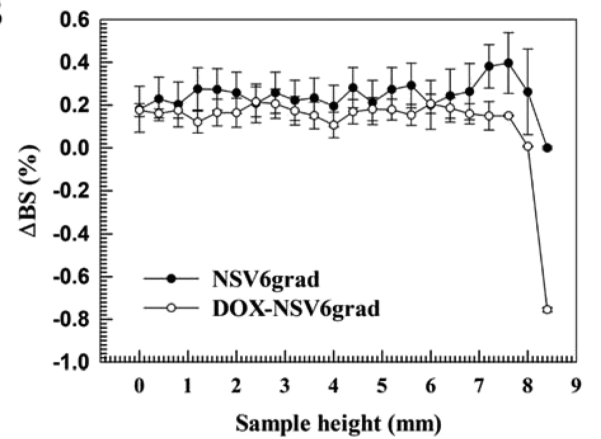

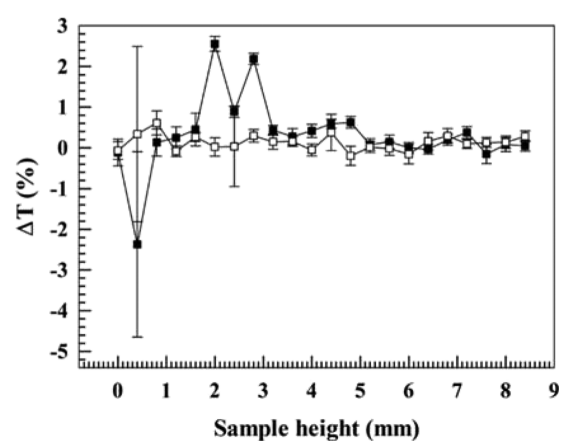

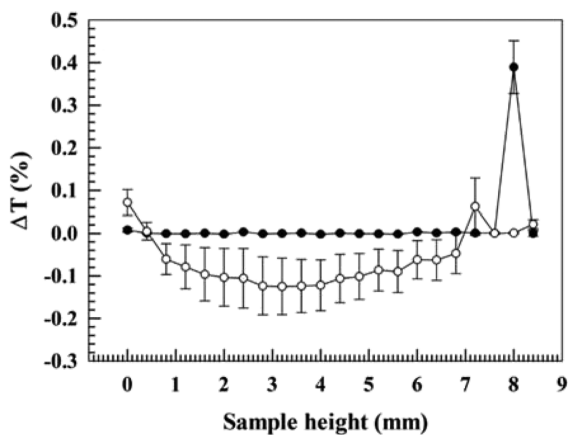

Figure 4. (A) $\Delta$ BS (A, left) and $\Delta T$ (A, right) for NSV1grad and DOX-NSV1grad. (B) $\Delta B S$ (B, left) and $\Delta T$ (B, right) for NSV6grad and DOXNSV6grad. The image is representative of three independent experiments \pm S.D. $(n=3)$.

in FBS (Figure 3A). Sizes of NSVs increased to $50 \mathrm{~nm}$ after 24 $\mathrm{h}$ of incubation and grew up to $500-800 \mathrm{~nm}$ after $72 \mathrm{~h}$ (Figure $3 \mathrm{~A})$. We speculated the hypothesis that protein corona started to cover particle surface after $8 \mathrm{~h}$ of incubation, thus forming a thickness layer on the surface of particles which increased NSV average sizes. ${ }^{24,70,72}$ NSV1grad and NSV6grad, with or without DOX, had a similar trend up to $8 \mathrm{~h}$ of incubation (Figure 3B); in fact, NSV6grad had slightly increased sizes $(\approx 250 \mathrm{~nm})$ than NSV1grad because of the lower amount of PEO unit in the NSVs, which hampered protein serum and lipoprotein penetration in the niosome bilayer. Pozzi et al. previously demonstrated that the time of interaction between nanoparticles and the protein serum of FBS can affect their binding to the liposomal surface, thus enriching the protein corona of nanoparticles. In particular, proteins with low affinity but high concentration earliest interact with lipid nanoparticles. Adsorbed proteins are then removed from nanoparticles and no large increase of size was finally obtained. The resulting protein corona is removed and then replaced by other proteins with lower concentrations, lower exchange rates, and higher affinities than the primary one. ${ }^{73}$ Moreover, the particle size increased after 3 days of serum incubation. Conversely, average sizes of NSV6grad, with or without DOX, increased significantly after $24 \mathrm{~h}$ of incubation because the protein corona covering nanocarriers becomes consistent and several proteins are adsorbed on the surface of NSV6grad, like nonPEGylated liposomes. ${ }^{68}$ Empty and DOX-NSV6grad showed a decrease of particle size after $72 \mathrm{~h}$ of incubation (Figure 3B). In this specific case, the osmotic pressure modified the internal supramolecular structure of NSVs after the interaction of serum albumin with surfactants of nanocarriers. Differences between NSV1grad and NSV6grad might depend on different surface charges of NSVs (Figure 1B); in fact, NSV6grad has a more net negative charge than NSV1grad and then strongly interacts with serum proteins. ${ }^{74}$

Turbiscan Lab Expert Analysis of DOX-NSVs. Turbiscan Lab Expert is basically used to predict the long-term stability of emulsions, solutions, and suspensions without 
A

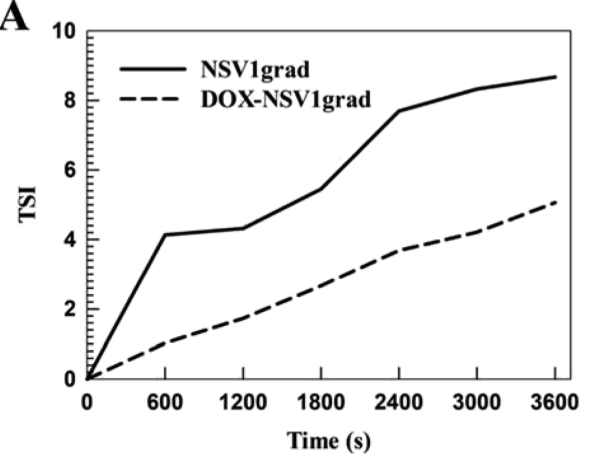

B

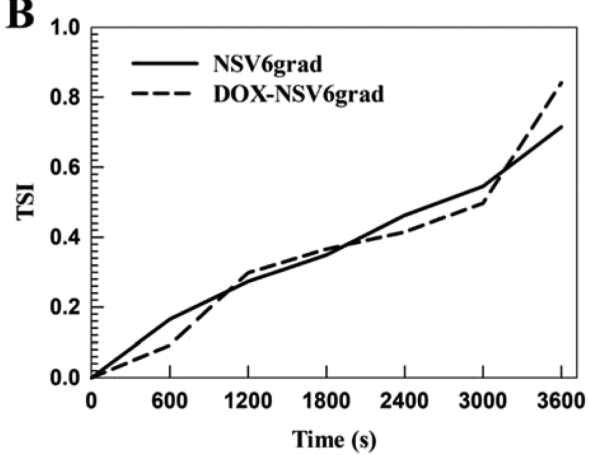

Figure 5. Kinetic destabilization profiles for NS1grad and DOX-NSV1grad (A) and NSV6grad and DOX-NSV6grad (B). The image is representative of three independent experiments \pm S.D. $(n=3)$.

A

DOX-NSVs grad

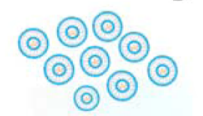

Hepes Serum/Hepes
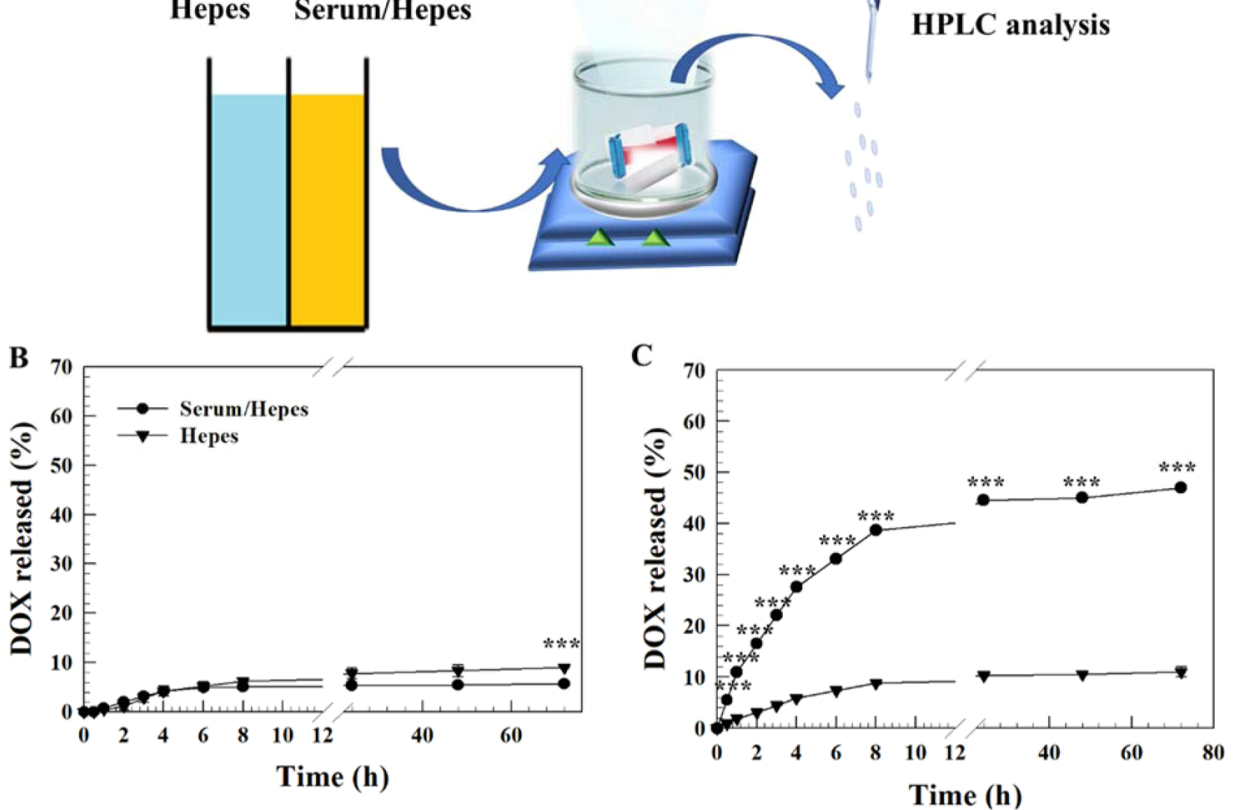

Figure 6. Schematic representation of DOX released from NSVsgrad in Hepes or Serum/Hepes (A), kinetics release of DOX from NSV1grad (B), and NSV6grad (C). Results are the average of three independent experiments \pm S.D. $(n=3)$. The $p$ values of $<0.05(*),<0.01(* *)$, and $<0.001$ $(* * *)$, with respect to Hepes.

disrupting formulations. ${ }^{75}$ Recently, Turbiscan technology was used to analyze the stability of polymeric and lipid nanocarriers and correlates the migration of particles to destabilization phenomena. ${ }^{75,76}$ Delta back scattering $(\Delta \mathrm{BS})$ and delta transmission $(\Delta T)$ profiles of empty and DOX-NSV1grad demonstrated that no significant variations of both signals occurred during the analysis. The samples $(\sim 10 \mathrm{~mm})$ were analyzed for $1 \mathrm{~h}$ and showed that changes of $\Delta \mathrm{BS}$ signals was below $\pm 2.5 \%$ and/or were closed to the baseline (Figure $4 \mathrm{~A}$ ). The loading of DOX inside NSV1grad did not significantly modify the $\Delta T$ and $\Delta \mathrm{BS}$ signals of nanocarriers (Figure 4A). These results were in agreement with data previously reported. ${ }^{77,78}$ Variations of $\Delta \mathrm{BS}$ and $\Delta T$ for samples within a range of $\pm 10 \%$ were not considered significant for the stability of nanocarriers (Figure 4), thus demonstrating no variation and/or migration of particles during the analysis as previously reported for other stable formulations. ${ }^{75,76}$ The presence of positive or negative $\Delta \mathrm{BS}$ and $\Delta T$ peaks below 2 $\mathrm{mm}$ and over $8 \mathrm{~mm}$ did not depend on unstable phenomena occurring during the analysis of NSVs, but they were because of the air at the bottom and/or the top of the cylindrical glass tube holding samples. ${ }^{76}$ Similar results were obtained for empty and DOX-NSV6grad. $\Delta B S$ and $\Delta T$ of empty and DOXNSV6 had values of $\pm 1 \%$ and overlapped the baseline signals (Figure 4B).

Destabilization kinetic analysis had different profiles for empty and DOX-loaded NSV1grad (Figure 5A). In particular, the Turbiscan stability index (TSI) was significantly higher for NSV1grad than DOX-NSV1grad (Figure 5A). We speculate that DOX can stabilize NSV1grad, thus reducing the final concentration of ammonium sulfate salt, which interacts with PEO units of nanocarriers. Conversely, TSI values are similar 
for empty NSV6grad and DOX-NSV6grad (Figure 5B). The long-term stability of both formulations, with/or without DOX, was further supported by the analysis of the average size as a function of incubation time. Indeed, diameter kinetic profiles of NSV6grad showed the lack of modifications for the hydrodynamic radius of nanocarriers during the Turbiscan analysis. Conversely, NSV1grad demonstrated a slight variation of the hydrodynamic diameter during the analysis, which was in agreement with the higher TSI value of NSV1grad than NSV6grad (Figure S2). These results were in agreement with DLS data (Figure 1B) as well as data previously reported, ${ }^{79}$ thus demonstrating that the increase of lipophilic properties of Sp20 compared to Tw20 improved the stability of NSVs.

In Vitro Release of DOX. Nanocarriers, particularly NSVs, release payloads by passive diffusion or degradation by the lipid bilayer after their internalization in a biological environment. ${ }^{42}$ The release study of NSV1grad and NSV6grad was carried out by the dialysis method in Hepes and Hepes/Serum $(40 / 60, \mathrm{v} / \mathrm{v})$ to mimic physiological conditions and the microenvironment after systemic administration (Figure 6A).

NSV1grad released a small percentage of DOX in Hepes and Hepes/Serum and a biphasic kinetic was obtained with $\sim 8 \%$ of DOX, which was released in the first $10 \mathrm{~h}$ of incubation (Figure 6). The drug release from NSV1grad up to $10 \mathrm{~h}$ depends on payloads adsorbed onto the surface of nanocarriers or leakage through the lipid bilayer, which are a small part of DOX crystallized in the aqueous core of NSV1grad. ${ }^{42}$ DOX (12\%) was slowly and continuous released up to $72 \mathrm{~h}$ (Figure 6B). Similar results were previously reported for DOX released from NSVs made from Tw80 and $\mathrm{Chol}^{44}$ and for PEGylated liposomes. ${ }^{44,80}$ The release kinetic of DOX from NSV6grad was similar to NSV1grad in Hepes (Figure 6C); conversely, DOX was released faster in $8 \mathrm{~h}$ of incubation from NSV6grad in Hepes/Serum than Hepes. A similar trend was observed for non-PEGylated liposomes; in particular, these studies demonstrated that the interaction between serum proteins and the bilayer of the nanocarriers increased the diameter of membrane pores and then favored the rapid release of entrapped hydrophilic payloads. ${ }^{81}$ PEGylation increased the stability of nanocarriers and less affects the modification of the bilayer and the leakage of the entrapped hydrophilic payloads. ${ }^{82-84}$

Differences of release kinetic between Hepes buffer and Hepes/Serum also depends on the serum protein composition, which can modify the supramolecular structure of NSVs and promote the leakage of payloads. ${ }^{85}$ This effect is specific for DOX-NSV6grad but it was not obtained for DOX-NSV1grad because of the presence of PEO units similar to PEG, which hamper the interaction of proteins with the surface of NSVs and avoid nanocarrier destabilization. ${ }^{68,86}$

The release kinetic of NSVs is not complete. The data showed that only a part of DOX was released form nanocarriers and saturation phase occurred during the analysis. This effect depends on the gel-like structure caused by $\mathrm{pH}$ gradient and remote loading procedure and the accumulation as crystals of DOX in the aqueous core of nanocarriers. ${ }^{87}$ The released fraction of the drug is improved for Serum/Hepes medium instead of Hepes alone.

The fitting of release data before saturation was analyzed using Noyes-Whitney (NW), square root law, power law models, and the resulting data were shown using an infinite reservoir system in a semi-infinite media (IR-SIM) (Figures S3-S6). The fraction of DOX, which is extrapolated during the analysis, was below $10 \%$ at $72 \mathrm{~h}$ (Figure 6A). A significant amount of DOX was released from NSV1grad in the first $24 \mathrm{~h}$ of incubation. Noyes Whitney model and square root model describe enough the release kinetic of DOX from NSVs (Figure S3C). The power law model did not allow a linear regression of data (Figure S3C). The release model of DOX in Serum/Hepes was below $6 \%$ at $72 \mathrm{~h}$ and data were lower than that obtained in Hepes medium (Figure 6A). All the resulting models fit experimental data; however, the data, collected using the power law model, include only four points during the analysis because this model has a lower performance than the other two models. The release of DOX from NSV6grad showed a biphasic model; in fact, DOX was quickly released in the first $24 \mathrm{~h}$ and then slowly released up to $72 \mathrm{~h}$. This kinetic model decreased the linearity of the correlation coefficient for DOX-NSV6grad compared to DOX-NSV1grad, and the resulting linear model is very poor (Figure 6). The release kinetics of DOX-NSV6grad decreased in Hepes and data (below $10 \%$ at $72 \mathrm{~h}$ ) is similar to that obtained for DOXNSV1grad (Figure 6B). All three models are representative of the release kinetics of DOX from NSVs, and the square root model showed the best correlation of data. These results were in agreement with meta-analysis review of different release kinetics extrapolated from drug-loaded nanocarriers, where phenomenological and mechanistic models are applied during the analysis. ${ }^{88}$ We previously demonstrated that fluorescein released from cubosomes was properly described using the square root law; ${ }^{89}$ conversely, in vitro release of zidovudine from niosomes was properly described using zero-order, firstorder, Higuchi, Korsmeyer-Peppas, and Hixson-Crowel models. ${ }^{90}$

In our case, the correlation coefficient of the data analyzed using different models was over 0.999. Based on this evidence, we supposed that data extrapolated using the Higuchi correlation coefficient described a diffusion-controlled release of DOX from NSVs. The $\mathrm{n}$ value calculated using the Korsmeyer-Peppas model was in the range from 0.23 to 0.54 , thus showing that the release of DOX from NSVs followed at the beginning of the Fickian diffusion law and then diffused through the erosion of lipid membranes. The release kinetic of DOX-NSVs, analyzed using the Hixson-Crowell model, further confirmed that the drugs were released from nanocarriers using a biphasic diffusion model, which was different from that previously reported. ${ }^{88}$

The square root law and power law models better described the release kinetic of NSVs because of the low amount of drug released up to $72 \mathrm{~h}$ of incubation and the quick saturation of receptor medium in the first hours of the experiment (Figures S3-S6). Furthermore, the NW model was used to describe specifically the first-order release kinetic model of DOX from NSVs because of its consistence and phenomenological impact for the release kinetic of drugs from colloidal nanocarriers. ${ }^{88}$ The NW model did not fit all the analyzed data in a single integration model, but it requires two integration models to have a better correlation for the analysis. These results may suggest a modification of the upper limit of saturation and the relative transfer of payloads versus the outside portion of the solvent interface surface in NSVs. The phenomenological analysis also demonstrated that the application of the power law model described the penetration of the solvent inside NSVs and the changes of surfactant properties and structures in the lipid bilayer during the release study. ${ }^{88}$

The release mechanism of NSVs was further analyzed using the two-phase Weibull equation model ${ }^{91}$ The results showed 
that the release mechanism of NSV1grad and NSV6grad in Hepes and Hepes/Serum was the representative of multiple processes occurring simultaneously during the release study according to $\mathrm{b}$ values $>1$ (Table $\mathrm{S} 1$ ). This effect may depend on the release kinetic of crystallized DOX from NSV1 and NSV6. In fact, DOX was first dissolved from crystals and diffused in the aqueous core of NSVs, and then was changed in neutral and soluble forms which passively diffused through the lipid bilayer. ${ }^{44,92}$

Cell Viability of DOX-NSVs. The cytotoxicity of DOXNSV1grad and NSV6grad was tested using the [3-(4,5dimethylthiazol-2-yl)-5-(3-carboxymethoxyphenyl)-2-(4-sulfophenyl)-2H-tetrazolium (MTT) assay on two different breast cancer cell lines, that is, MCF-7 and MDA MB 468. The MTT test was carried out as a function of time and drug concentration, and both cell lines were treated for 24, 48, and $72 \mathrm{~h}$ using an equivalent dosage of DOX in the range from 0.1 to $5 \mu \mathrm{M}$ as reported below: free DOX, empty NSV1grad, empty NSV6grad, DOX-NSV1grad, and DOX-NSV6grad (Figures 7 and 8). Empty NSV1grand and NSV6grad (controls) were tested at the same equivalent concentrations of DOX-NSVs used during the experiments, which were obtained based on differences between the drug and NSV concentration. Empty NSV1grad and NSV6grad are not toxic at different tested concentrations (Figure S7). The cytotoxicity of DOX on MCF-7 cells was time but not dose dependent (Figure 7). Indeed, the cytotoxicity of free DOX was similar by comparing at 0.01 and $0.1 \mu \mathrm{M}$ drug concentrations at $24 \mathrm{~h}$ (Figure 7A), $48 \mathrm{~h}$ (Figure 7B), and $72 \mathrm{~h}$ (Figure 7C). Conversely, the cytotoxic effect of free DOX, which was measured as the cell viability percentage, increased by increasing the incubation time from 24 to $72 \mathrm{~h}$ at 0.01 and $0.1 \mu \mathrm{M}$ of DOX (Figure 7). Conversely, the cytotoxicity of DOX-NSV1grad and DOX-NSV6grad on MCF-7 was time and dose dependent (Figure 7). As reported in Figure 7, DOXNSV6grad shows higher cytotoxicity on MCF-7 than the free drug and DOX-NSV1grad (Figure 7); these data were in agreement with the $\mathrm{IC}_{50}$ values of both NSVs (Table 1). Differences of cytotoxicity between NSV1grad and NSV6grad, which are statistically different for all tested concentrations and time points (Table S2), may depend on physicochemical properties of NSVs. In fact, nanocarriers with a net negative surface charge ( $\zeta$-potential below $-40 \mathrm{mV}$ ) were taken up by cancer cells higher than nanocarriers with a less negative value of $\zeta$-potential. ${ }^{93}$ In fact, different studies demonstrated that negatively charged liposomes made from phosphatidylserine phosphatidylglycerol, or phosphatidic acid were taken up better and faster from endocytic cells than neutral liposomes ${ }^{94}$ because of the presence of specific receptors binding negatively charged particles, which are present on the surface of cancer cells. ${ }^{95}$ Moreover, the higher content of PEO units on the NSV1 surface in comparison with NSV6 may reduce the interaction and then the internalization rate of nanovesicles from cells, in a similar way as PEG reduces the uptake of PEGylated nanocarriers, especially in vitro. ${ }^{96}$

Similar experiments were obtained for MDA MB 468 cells. In this case, the cytotoxicity activity of DOX on MDA MB 468 cells was time and dose dependent for all the tested concentrations and was higher than that obtained for MCF-7 cells (Figure 8). Aziz and coworkers demonstrated a similar difference of DOX cytotoxicity in MDA MB 468 and MCF-7 cells; ${ }^{97}$ in fact, they demonstrated that differences of DOX cytotoxicity in MDA MB 468 (high) and MCF-7 (low) cells
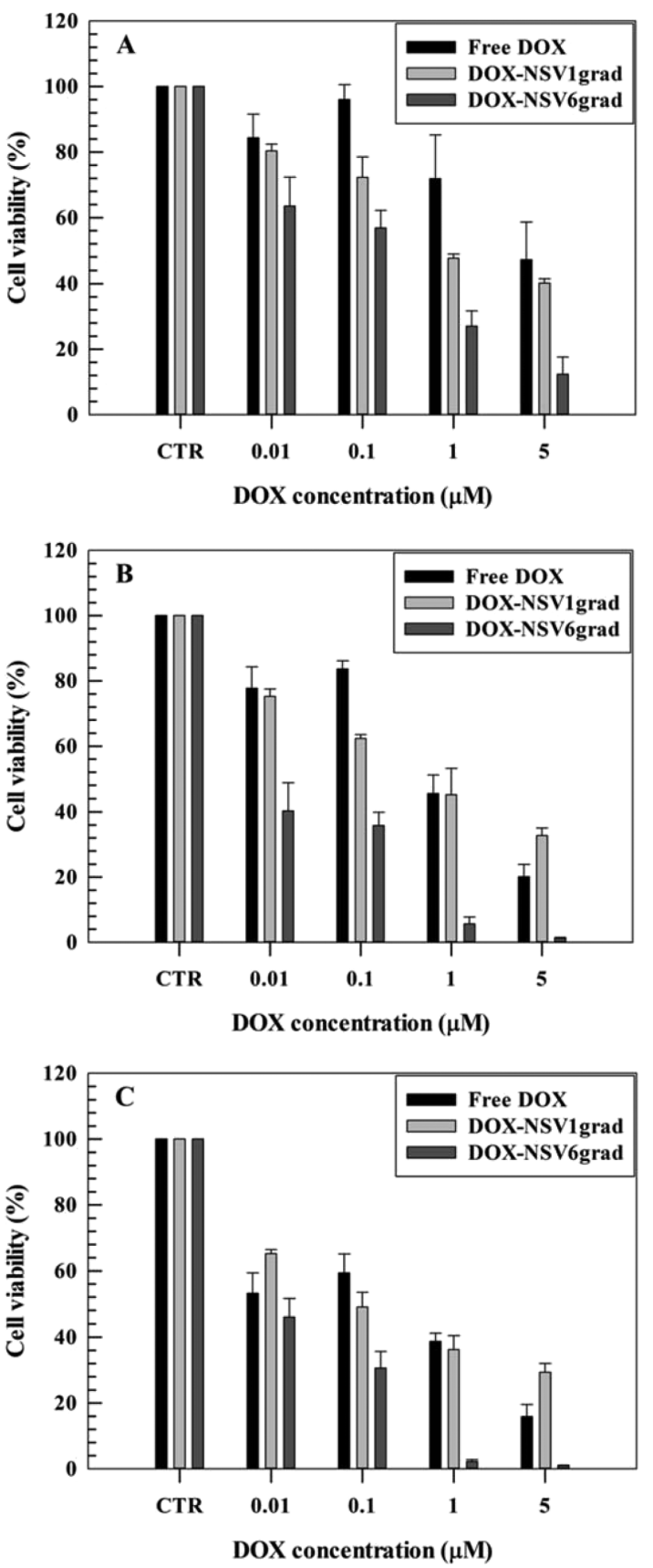

Figure 7. MCF-7 cell viability upon incubation times at 24 (A), 48 (B), and $72 \mathrm{~h}$ (C) with different concentrations of free DOX, DOXNSV1grad, and DOX-NSV6grad. Results are the average of three independent experiments \pm S.D. $(n=3)$. The statistical analysis of cytotoxicity data is available in the Supporting Information (Table S2).

depended on the different expressions of MEN1, an important tumor suppressor gene, in both cell lines. Furthermore, there is a negative correlation between MEN1 and estrogen receptor expressions in breast cancer cells. For this reason, DOX significantly decreased the expression of MEN1 in MDA MB 468 cells, but not in MCF-7. ${ }^{97}$ Free DOX at $1 \mu \mathrm{M}$ is more toxic on MDA MB 468 than DOX-NSV1grad at the same concentration at 24,48 , and $72 \mathrm{~h}$ of incubation. In fact, the cell viability of free $\mathrm{DOX}$ at $1 \mu \mathrm{M}$ was decreased at different incubation times $(24-72 \mathrm{~h})$ compared DOX-NSV1grad (Figure 8 ). These results were opposite to cytotoxic effects 

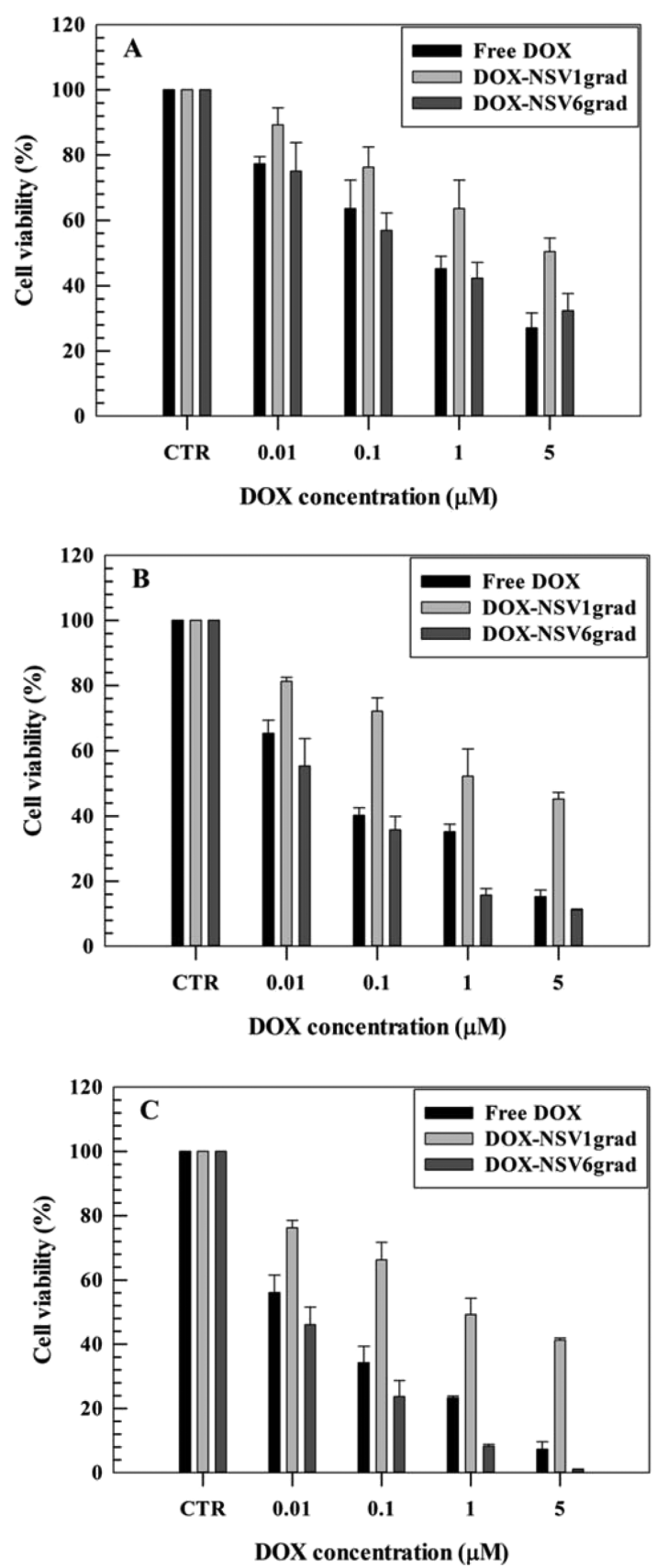

Figure 8. MDA MB 468 cell viability upon incubation times at 24 (A), 48 (B), and $72 \mathrm{~h}$ (C) with different concentrations of free DOX, DOX-NSV1grad, and DOX-NSV6grad. Results are the average of three independent experiments \pm S.D. $(n=3)$. The statistical analysis for the cytotoxicity data is available in the Supporting Information (Table S2).

Table 1. IC $_{50}$ DOX, DOX-NSV1grad, and DOX-NSV1grad at 48 and $72 \mathrm{~h}$ on MCF-7 and MDA MB 468 Cell Lines

\begin{tabular}{llcl} 
& \multicolumn{2}{c}{ IC $_{50}$ values $(\mu \mathrm{M})$} \\
\cline { 2 - 4 } cell lines & \multicolumn{1}{c}{ treatment } & $48 \mathrm{~h}$ & $72 \mathrm{~h}$ \\
MCF-7 & DOX & 0.83 & 0.20 \\
MCF-7 & DOX-NSV1grad & 0.72 & 0.12 \\
MCF-7 & DOX-NSV6grad & 0.06 & 0.06 \\
MDA MB 468 & DOX & 0.06 & 0.02 \\
MDA MB 468 & DOX-NSV1grad & 1.68 & 1.22 \\
MDA MB 468 & DOX-NSV6grad & 0.02 & 0.01
\end{tabular}

obtained for MCF-7 cells (Figure 8). Differences between MCF-7 and MDA MB 468 cells depended on the higher responsiveness of MDA MB 468 versus DOX. ${ }^{98}$ Indeed, DOXNSV1grad had several PEO units in Tw20 which decreased the interaction between DOX-NSV1grad and MDA MB 468 cells, thus decreasing the in vitro cytotoxic effect of the payload, although this cell line was highly responsive to DOX as previously reported. ${ }^{98}$ The cytotoxicity activity of DOX on MDA MB468 cells increased by using DOX-NSV6grad; this effect is time and dose dependent and DOX-NSV6grad was more cytotoxic than free DOX and/or DOX-NSV1grad (Figure 8). The resulting data were in agreement with the significant reduction of $\mathrm{IC}_{50}$ values obtained at the same incubation time and drug concentration for DOX-NSV6grad (Table 1). The results were similar to data previously reported for anticancer cells treated in vitro with NSVs. ${ }^{44}$ This effect might depend on the passive accumulation of NSVs in the tumor tissue and the relative decrease of side effects, which can allow NSVs to overcome drug resistance. ${ }^{99}$ This is the reason supporting the hypothesis that the amount of the DOX loaded in NSV6grad significantly increased the cytotoxicity of the payload in cancer cells. ${ }^{100}$

Rhodamine-DHPE labeled NSV1grad and NSV6grad were used to qualitatively evaluate the intracellular uptake in MCF-7 and MDA MB 468 cells. Breast cancer cells were incubated with fluorescent NSVs for $24 \mathrm{~h}$. Representative confocal fluorescent images of rhodamine-DHPE labeled NSV1grad and NSV6grad are shown in Figures 9 and S8. The cell nuclei were detected with blue fluorescence after staining cells with DAPI, while NSV1grad and NSV6grad were labeled in red because the rhodamine-DHPE included the bilayer of NSVs. The intracellular uptake of rhodamine-DHPE NSV6grad in MCF-7 and MDA MB 468 cells was time dependent (Figure 9). The rhodamine-DHPE NSV6grad was detected both in the membrane surface and cytosol of MCF-7 cells after $6 \mathrm{~h}$ of incubation (Figure 9), while the rhodamine-DHPE NSV6grad was accumulated in the cytosol and perinuclear region of cells after $24 \mathrm{~h}$ of incubation (Figure S8), as previously reported. ${ }^{101}$ The Z-stack analysis endorsed the massive intracellular detection of the fluorescent NSV6grad after $24 \mathrm{~h}$ of incubation (Figure S9), according to data previously reported. ${ }^{100}$ A similar result was obtained for MDA MB 468 cells. Rhodamine-DHPE NSV6grad was taken up quicker inside MDA MB 468 cells than MCF-7 cells after 6 h of incubation (Figure S8). Results agreed with the data previously reported which demonstrated that the particle size, composition, and surface charge of nanocarriers affected their interaction and uptake with breast cancer cells. Moreover, this interaction is related to the density of specific receptors on breast cancer cells. ${ }^{102}$ In fact, Song et al. previously demonstrated that particle uptake in MCF-7 and MDA MB 468 depended on the EGFR expression on cellular membranes, which is $10^{2}$-fold higher for MDA MB 468 than MCF-7 cells. ${ }^{102}$ Conversely, rhodamine-DHPE NSV6grad was significantly accumulated in the cytosol and perinuclear region after $24 \mathrm{~h}$ of incubation (Figure S8). Results were in agreement with the $Z$-stack analysis at the same incubation time (Figure S9). Rhodamine-DHPE NSV1grad had a lower intracellular uptake than rhodamine-DHPE NSV6grad in both breast cancer cell lines. The intracellular uptake of rhodamineDHPE-NSV1grad in MCF-7 or MDA MB 468 cells was time dependent, showed a low interaction in both cell lines after $6 \mathrm{~h}$ of incubation, and a significant increase after $24 \mathrm{~h}$ of incubation (Figures S8 and S9). 


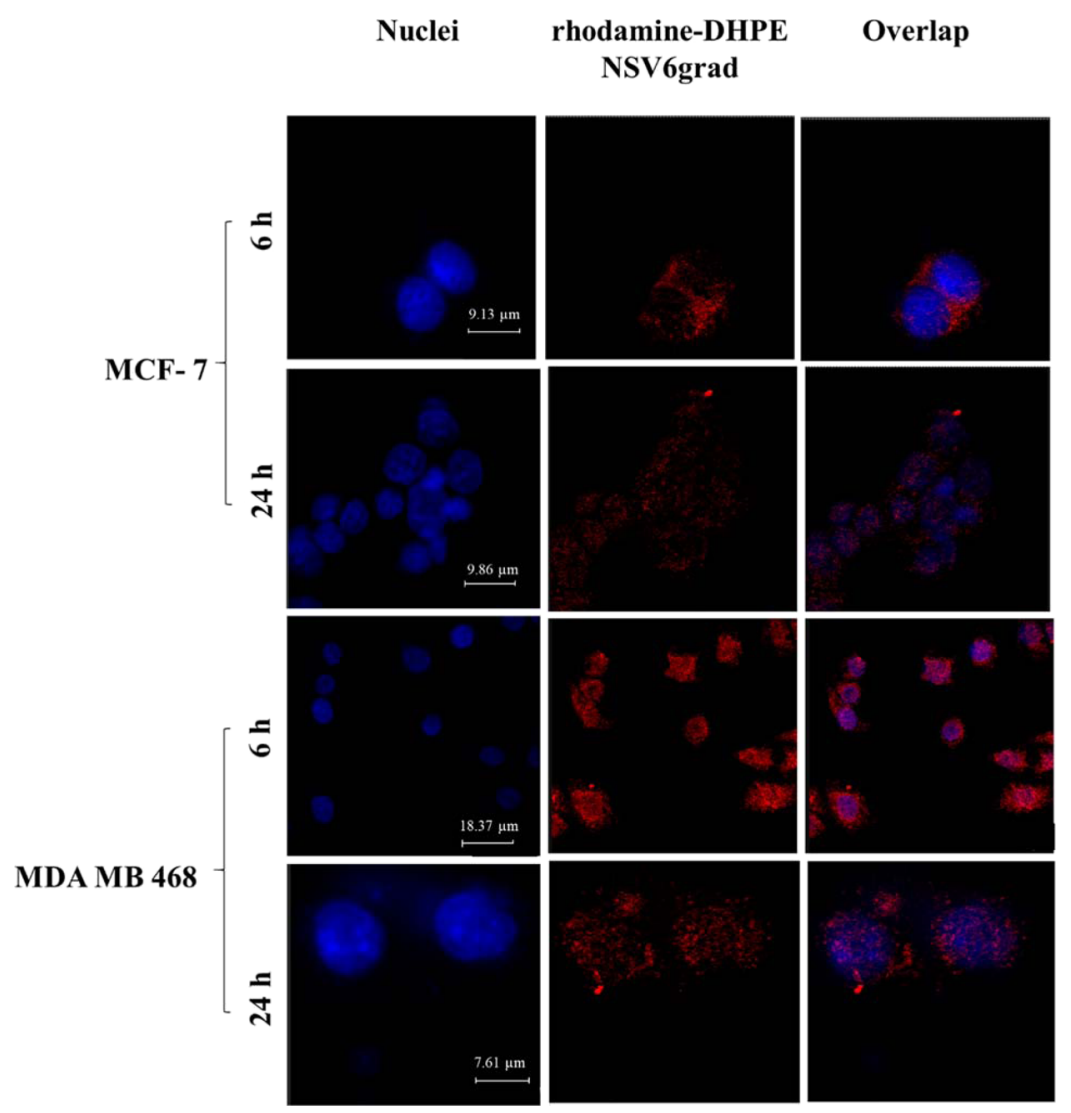

Figure 9. Confocal microscopy analysis of rhodamine-DHPE NSV6grad at 6 and 24 h post incubation with MCF-7 and MDA MB 468 cells. The image is representative of three independent experiments $(n=3)$.

\section{CONCLUSIONS}

We developed NSVs made from surfactants with different physicochemical properties to treat metastatic breast cancer and improve the efficacy of anticancer therapy in vitro. NSVs, having physicochemical properties suitable for potential in vitro and in vivo applications, were selected and loaded with DOX. $\mathrm{pH}$ gradient and remote loading procedure increase the amount of the drug inside nanocarriers, and thus the EE of DOX. DOX-NSV1grad and DOX-NSV6grad had average sizes below $120 \mathrm{~nm}$, narrow size distribution, and a net negative charge. NSVs with and without DOX were stable and had a sustained release of the drug up to $72 \mathrm{~h}$. In vitro studies, using metastatic and non-metastatic breast cancer cells (MCF-7 and MDA MB 468 cells), demonstrated that DOX-NSV6grad were better internalized in both cancer cell lines than DOXNSV1grad, and the intracellular uptake is a time-dependent process. The anticancer effect of DOX-NSV6grad was obtained after $72 \mathrm{~h}$ of incubation in MDA MB 468 cells, and the anticancer effect was improved in metastatic breast cancer cells than non-metastatic (MCF-7 cells) breast cancer cells. NSVs increased the anticancer effect in MCF-7 and MDA MB 468 cells compared to free DOX at the same dosage and incubation time. The results seemed to suggest that DOX-NSV6grad could be a promising nanocarrier for the potential treatment of metastatic breast cancer.

\section{EXPERIMENTAL SECTION}

Chemicals. Tween 20 (Tw20), Hepes salt, [N-(2hydroxyethyl)piperazine- $N^{\prime}$-(2-ethanesulfonic acid)], polycarbonate Whatman nucleopore tracketched membranes (cut-off
$0.1 \mu \mathrm{m})$, DPPG, Sephadex G75, $\left(\mathrm{NH}_{4}\right)_{2} \mathrm{SO}_{4}$, and $\mathrm{H}_{2} \mathrm{CO}_{3}$ were purchased from Sigma-Aldrich (Sigma-Aldrich SRL, Milan, Italy). Chol and sorbitan monolaurate (Span20) were obtained from Acros Organics products (Acros Organics BVBA Geel, Belgium). Cellulose acetate membrane (cut-off $8 \mathrm{kDa}$ ) was obtained from Prodotti Gianni S.p.A. (Milan, Italy). MTT assay was obtained from Promega (Madison, WI, USA). DOX was obtained by D.B.A. (Milan, Italy). MCF-7 and MDA MB 468 were obtained from American Type Culture Collection (ATCC, LGC Standards, Teddington, UK). High-glucose Dulbecco's modified Eagle's minimal essential medium (DMEM), Roswell Park Memorial Institute Medium (RPMI1640), heat-inactivated FBS, trypsin-EDTA (1X) solution, and penicillin-streptomycin solution were obtained from Gibco (Invitrogen Corporation, Giuliano Milanese, Milan, Italy). Lissamine rhodamine B 1,2 dihexadecanoyl-sn-glycero3-phosphoethanolamine triethylammonium salt (rhodamine BDHPE) was purchased from Invitrogen (Life Technologies Corporation, Grand Island, NY, USA). All other chemical reagents were obtained from Sigma-Aldrich (Milan, Italy) or Thermo Fisher Scientific (Waltham, MA USA) and are used without further purification.

Synthesis of NSVs. NSVs are synthetized using Chol, Tw21, and Tw20 at different molar concentrations, as reported in Table 2. NSVs were obtained using the TLE method as previously reported. ${ }^{44}$ Briefly, surfactants, Chol, and rhodamine B-DHPE $(10 \mu \mathrm{L})$, if necessary, were dissolved in a chloroform/methanol mixture $\left(\mathrm{CHCL}_{3} / \mathrm{CH}_{3} \mathrm{OH}, 3: 1, \mathrm{v} / \mathrm{v}\right)$, and a thin layer film was obtained after removing the organic solvent by a rotary evaporator (Laborota 4000, Heidolph, Delchimica, Naples, Italy). When required, the final concen- 
Table 2. Synthesis of NSVs Made from Tw21, Tw20, and Sp20 at Different Molar Concentrations

\begin{tabular}{clcccc} 
samples & $\begin{array}{c}\text { Tw21 } \\
(\mathrm{mM})\end{array}$ & $\begin{array}{c}\text { Tw20 } \\
(\mathrm{mM})\end{array}$ & $\begin{array}{c}\text { Sp20 } \\
(\mathrm{mM})\end{array}$ & $\begin{array}{c}\text { DPPG } \\
(\mathrm{mM})\end{array}$ & $\begin{array}{c}\text { Chol } \\
(\mathrm{mM})\end{array}$ \\
NSV1 & & 15 & & & 15 \\
NSV2 & 3.75 & 11.25 & & & 15 \\
NSV3 & 7.50 & 7.50 & & & 15 \\
NSV4 & 11.25 & 3.75 & & & 15 \\
NSV5 & 15 & & & 0.15 & 15 \\
NSV6 & & 0.15 & 14.70 & & 15 \\
\hline
\end{tabular}

tration of rhodamine B-DHPE per NSVs was $0.1 \% \mathrm{w} / \mathrm{w}$. The setup parameters of the rotary evaporator were $90 \mathrm{rpm}$, room temperature, and pressure at $10 \mathrm{mmHg}$. NSVs with Span 20 (Sp20) (NSV6, Table 2) were obtained by evaporating the organic solvent from the lipid mixture and forming a thin layer film at $60{ }^{\circ} \mathrm{C}$. ${ }^{44}$ Thin layer films were hydrated with Hepes buffer (10 mM, pH 7.4) or DOX solution (Hepes buffer, 100 $\mu \mathrm{g} / \mathrm{mL}$ ) and sonicated at $60{ }^{\circ} \mathrm{C}$ for $10 \mathrm{~min}$ (amplitude $=60 \%$ nominal power, cycle $=1$ ) using a probe sonicator (Hielscher, model UP200H, Teltow, Germany). To remove unentrapped drug and nonassembled surfactants, NSVs or DOX-NSVs were purified by size exclusion chromatography on Sephadex G75 glass columns, as previously reported.

DOX pH Gradient and Remote Loading Procedure. The amount of DOX-loaded NSV1 and NSV6 was increased by applying a $\mathrm{pH}$-remote loading procedure as previously reported. ${ }^{44}$ Briefly, a thin layer film of NSV1 and NSV6 was obtained using the TLE method herein reported, and the resulting film was hydrated by adding $5 \mathrm{~mL}$ of $\left(\mathrm{NH}_{4}\right)_{2} \mathrm{SO}_{4}$ (300 mM, pH 4.0), vortex mixed for $5 \mathrm{~min}$ at $15-20 \mathrm{~Hz}$, and incubated at $37{ }^{\circ} \mathrm{C}$ for $12 \mathrm{~h}$ under continuous stirring with a DOX solution in order to have a final drug concentration of $100 \mu \mathrm{g} / \mathrm{mL}$. Multilamellar vesicles were extruded by $100 \mathrm{~nm}$ polycarbonate-stacked membranes (twice) using an iron thermo barrel extruder (Lipex Biomembranes, Vancouver, BC, Canada), and unilamellar vesicles were then collected. Vesicles were neutralized with a solution of $\mathrm{Na}_{2} \mathrm{CO}_{3}(40 \mu \mathrm{L})$.

Physicochemical Characterization of NSVs. Average sizes, size distribution (PDI), and Z-potential ( $\zeta$-potential) of NSVs were analyzed using a DLS. Samples were diluted with isosmotic double distilled pyrogenic free water $(1: 10 \mathrm{v} / \mathrm{v})$ to avoid multiple scattering phenomena and analyzed at $25{ }^{\circ} \mathrm{C}$ with a Malvern Zetasizer Nano ZS (Malvern Instruments Ltd., United Kingdom) as previously reported. ${ }^{44}$ DLS was set up according to the software's instructions, and the parameters were: real refractive index 1.59 , imaginary refractive index 0.0 , medium refractive index 1.330 , medium viscosity $1.0 \mathrm{mPa} s$ and medium dielectric constant 80.4 for sizes and PDI, Smoluchowsky constant $F(\mathrm{Ka})$ of 1.5 , and $\mathrm{He} / \mathrm{Ne}$ laser doppler anemometry $(633 \mathrm{~nm})$ and nominal power of $5.0 \mathrm{~mW}$ for $\zeta$-potential. The measurements were triplicates of three different batches ( 5 replications for each batch).

TEM Analysis of NSVs. Particle size and shape of NSVs were measured using TEM as previously reported. ${ }^{103}$ Briefly, NSVs were diluted 1:100 (v/v) in deionized water and held onto a 200-mesh formvar-coated copper grid (Taab Laboratories, UK). The resulting samples were stained with an uranyl acetate solution $(2 \%, \mathrm{w} / \mathrm{v}, 5 \mathrm{~min})$ and dried at $23{ }^{\circ} \mathrm{C}$. Images were acquired at $200 \mathrm{kV}$ using a JEM 2010 microscope (JEOL, MA, USA).
EE of DOX-NSVs. The high-performance liquid chromatography (HPLC) apparatus was used to quantify DOX inside NSVs. ${ }^{44}$ A Waters Liquid Chromatography apparatus was equipped with a model 1525 binary solvent pump and a 2996 photodiode array detector. The mobile phase was on-line degassed directly using the Degassex, mod. DG-400 (Phenomenex, Torrance, CA, USA). A Gemini reverse phase C18 packing column $(4.6 \mathrm{~mm} \times 250 \mathrm{~mm} ; 5 \mu \mathrm{m}$ particle size; Phenomenex, Torrance, CA, USA), and a disposable Security Guard column $(4.0 \times 3.0 \mathrm{~mm}, 5 \mu \mathrm{m}$ particle size; Phenomenex, Torrance, CA, USA) was used for drug detection. The column was warmed up at $25 \pm 1{ }^{\circ} \mathrm{C}$ using a Waters Temperature Control Module II (Waters Spa, Milford, MA, USA). Data were acquired and processed using Empower v.2 Software (Waters Spa, Mil-ford, MA, USA). DOX was eluted under isocratic conditions: 40:60 v/v, $\mathrm{H}_{2} \mathrm{O}+0.05 \%(\mathrm{v} /$ v) TFA $/ \mathrm{AcN}+0.05 \%(\mathrm{v} / \mathrm{v})$, and flow rate of $1 \mathrm{~mL} / \mathrm{min}$. DOX was detected using a fluorescent detector at an emission wavelength $\left(\lambda_{\text {emi }}\right)$ of $590 \mathrm{~nm}$ and excitation wavelength $\left(\lambda_{\text {exc }}\right)$ of $490 \mathrm{~nm}$, respectively. Empty NSVs were used as the blank during the analysis. The retention time of DOX was $4.29 \mathrm{~min}$ (Figure S10). DOX concentration was measured using the following equation (eq 1)

$$
\mathrm{AUC}=8 \times 10^{6} x+3 \times 10^{6} ; \quad R^{2}=0.9997
$$

where, $x$ is the drug concentration $(\mu \mathrm{g} / \mathrm{mL})$ and AUC is the area under the curve. Measurements were in the linear concentration range of $0.25-25 \mu \mathrm{g} / \mathrm{mL}$ using an external calibration curve.

DOX-NSVs was quantified by dissolving NSVs with isopropyl alcohol $(1: 1 \mathrm{v} / \mathrm{v})$, and then analyzed by HPLC. The EE of DOX-loaded NSVs (EE \%) was calculated using the following equation (eq 2)

$$
\mathrm{EE}(\%)=\frac{\mathrm{DOX}_{\mathrm{E}}}{\mathrm{DOX}_{\text {Tot }}} \times 100
$$

where, $\mathrm{DOX}_{\mathrm{E}}$ is the amount $(\mu \mathrm{g})$ of drug loaded into NSVs and $\mathrm{DOX}_{\text {Tot }}$ is the amount of drug $(\mu \mathrm{g})$ added to NSVs during the preparation procedure.

NSV Serum Stability. The serum stability of NSVS was carried out as previously reported. ${ }^{68}$ NSV1 and NSV6 (400 $\mu \mathrm{L}$ ) were incubated with $2 \mathrm{~mL}$ of the medium [Hepes buffer/ FBS, 40:60, (v/v)] at $37 \pm 2{ }^{\circ} \mathrm{C}$ and maintained under magnetic stirring (400 rpm) for $72 \mathrm{~h}^{.71}$ At specific time points, $50 \mu \mathrm{L}$ of the mixture was collected and replaced with fresh medium. Samples were suitably diluted and then analyzed using DLS, as herein reported in the Experimental section Physicochemical Characterization of NSVs. Sterile conditions were maintained during the experiments to preserve NSVs from bacterial contamination.

Turbiscan Lab Expert of DOX-Loaded NSVs. The longterm stability of NSV1 and NSV6, with or without DOX, was tested using a Turbiscan Lab Expert apparatus (Formulaction, L'Union, France). ${ }^{75,76}$ Briefly, NSVs were diluted tenfold using Hepes buffer (10 mM, pH 7.4) and then the resulting suspensions $(6 \mathrm{~mL})$ were held in a glass cylinder tube and scanned up to $10 \mathrm{~mm}$ (height of holder) at room temperature for $1 \mathrm{~h}$. The analysis was carried out using a pulsed near infrared LED at a wavelength of $880 \mathrm{~nm}$. Two synchronous optical detectors transmitting and back scattering incident light at 180 and $45^{\circ}$ were used during the analysis, respectively. The variation of the volume fraction (migration) or diameter 
(coalescence) for NSVs was measured as a function of BS and/ or transmission $(T)$ signal variation versus height of the sample. The variation of average sizes associated with nanocarriers during the analysis was also evaluated for NSV6grad and DOX-NSV6grad and reported as a function of time. The kinetic destabilization profiles were extrapolated and reported as TSI versus time. Data were processed using Turby Soft 2.3.1.125.

Release of DOX from NSVs. The dialysis bag diffusion technique was used to study the release kinetic of DOX from NSVs. DOX-loaded NSV1 and NSV6 $(2 \mathrm{~mL})$ were placed in cellulose acetate membranes (cut-off $8 \mathrm{kDa}$ ), previously hydrated in water at room temperature for $60 \mathrm{~min}$. A dialysis bag with DOX-NSVs were soaked into crystallizing dishes containing $200 \mathrm{~mL}$ of Hepes buffer $(10 \mathrm{mM}$, pH 7.4) or Hepes buffer/FBS (40:60, v/v) and maintained under magnetic stirring at $37 \pm 2{ }^{\circ} \mathrm{C}$. The crystallizing dishes were covered with aluminum foils to avoid evaporation of receptor medium and the modification of the experimental setup. At specific time points, $1 \mathrm{~mL}$ of receptor medium was withdrawn and replaced with the same volume of fresh medium (Hepes or Hepes/FBS). Serum proteins were removed before the analysis for DOX samples released in Hepes/FBS as previously reported with some modifications. ${ }^{39,104}$ Briefly, $300 \mu \mathrm{L}$ of $\mathrm{MeOH}$ were added to $100 \mu \mathrm{L}$ of the sample (Hepes/FBS containing DOX released from NSV1 and NSV6). The resulting sample was mechanically stirred for $1 \mathrm{~min}$ and then centrifuged at $12,000 \mathrm{~g}$ at $4 \pm 2{ }^{\circ} \mathrm{C}$ for $10 \mathrm{~min}$.

The amount of DOX released from NSVs in the receptor media was quantified at different time points (from 30 min up to $72 \mathrm{~h}$ ) using an HPLC apparatus as herein reported (methods section EE of DOX-NSVs). The drug release was calculated according to the following equation (eq 3)

$$
\% \operatorname{Rel}_{t}=\frac{[\mathrm{drug}]_{\text {Rel }}}{[\mathrm{drug}]_{\text {Ent }}} \times 100
$$

where, \% $\mathrm{Rel}_{t}$ is the drug release percentage at time $(t)$, $[\mathrm{drug}]_{\mathrm{Rel}}$ is the drug concentration in the receptor fluid, and $[\mathrm{drug}]_{\text {Ent }}$ is the amount of the drug entrapped inside NSVs.

The resulting data were fitted using different mathematical models and, particularly, the square root, two-phase Weibull, NW, and Peppas models. ${ }^{88}$ The evaluation of performances was appreciated by calculating the correlation coefficient and number of consecutive points, which were reliably estimated.

Cytotoxicity Test. MDA MB 468 and MCF-7 human breast cancer cells were obtained from ATCC (USA). Cells were seeded at $37{ }^{\circ} \mathrm{C}$ with $5 \% \mathrm{CO}_{2}$ in DMEM with $10 \%(\mathrm{v} / \mathrm{v})$ heat inactivated FBS, $1 \mathrm{mM}$ glutamine, and $1 \%(\mathrm{v} / \mathrm{v})$ penicillin/streptomycin solution. Fresh medium was replaced every $48 \mathrm{~h}$. When $\sim 80 \%$ confluence was reached, both cell lines were used for evaluating the cytotoxicity of different formulations. Cell viability was assessed by the MTT test. Both cell lines were seeded into 96 -well plates at a density of $5 \times 10^{3}$ cells per well and incubated for $24 \mathrm{~h}$ at $37^{\circ} \mathrm{C}$ to promote their adhesion and confluence. After $24 \mathrm{~h}$, cell culture media were removed and replaced with fresh medium containing different concentrations of free DOX, DOX-NSV1, and DOX-NSV6 in the range from 0.01 to $5 \mu \mathrm{M}$ of the drug or an equivalent amount of empty NSVs at the same tested concentrations of DOX-NSVs. After 24, 48, and $72 \mathrm{~h}$, incubation medium was removed and a MTT solution $(5 \mathrm{mg} / \mathrm{mL}$ in PBS buffer) was added to each well and incubated for further $3 \mathrm{~h}$. The supernatant from each well was removed and $200 \mu \mathrm{L}$ of a dimethyl sulfoxide/ethanol solution $(1: 1 \mathrm{v} / \mathrm{v})$ were added to dissolve the resulting colored formazan crystals. Plates were then gently shaken at $230 \mathrm{rpm}$ (IKA KS 130 Control, IKA WERKE GMBH \& Co, Staufen, Germany) for $20 \mathrm{~min}$. The absorbance of various samples was measured with an ELISA microplate reader (Labsystems mod. Multiskan MS, Midland, $\mathrm{ON}$, Canada) at $570 \mathrm{~nm}$ in absorbance and $670 \mathrm{~nm}$ in emission. The percentage of cell viability was evaluated using the following equation (eq 4)

$$
\text { cell viability }(\%)=\frac{\mathrm{Abs}_{\mathrm{t}}}{\mathrm{Abs}_{\mathrm{C}}} \times 100
$$

where $\mathrm{Abs}_{\mathrm{t}}$ is the absorbance of treated cells and $\mathrm{Abs}_{\mathrm{C}}$ is the absorbance of control (untreated) cells.

Confocal Fluorescent Microscopy Imaging. Cellular uptake and intracellular localization of rhodamine-DHPE NSV1grad and rhodamine-DHPE NSV6grad tested in MDA MB 468 and MCF-7 cell lines. ${ }^{100}$ Briefly, $4.0 \times 10^{5}$ cells $/ \mathrm{mL}$ were seeded in six-well culture plates at $37{ }^{\circ} \mathrm{C}, 5 \% \mathrm{CO}_{2}$ with cell culture medium and onto a sterile glass slide. After $24 \mathrm{~h}$, cell lines were treated with rhodamine-DHPE NSV1grad and rhodamine-DHPE NSV6grad for 6 and 24 h, respectively. At each incubation time, the cell culture medium was removed, and cells were washed 3 times in PBS for $5 \mathrm{~min}$. Cells were then fixed on the sterile glass slides using $1 \mathrm{~mL}$ of a $70 \% \mathrm{v} / \mathrm{v}$ ethanol solution. Each slide was further washed 3 times with PBS and $2 \mathrm{~mL}$ of samples was added to each well. The plates were stored at $4{ }^{\circ} \mathrm{C}$ up to the CLSM analysis. Before analysis, cover slides were positioned over the glass slides using a $70 \%$ $\mathrm{v} / \mathrm{v}$ glycerol solution to remove enclosed air and then fixed with transparent glue. Nuclei were stained with DAPI (blue color) (Thermo Fisher Scientific, USA) and rhodamine-DHPE NSVs were visualized in red.

Statistical Analysis. The results are expressed as mean \pm standard deviation. The statistically significant difference was performed using analysis of variance (ANOVA), with a Tukey's multiple comparison test as the post hoc test. The Brown-Forsythe test confirmed the homogeneity of variances for different samples through the analysis. A $p$ value $\leq 0.05$ is considered statistically significant.

\section{ASSOCIATED CONTENT}

\section{Supporting Information}

The Supporting Information is available free of charge at https://pubs.acs.org/doi/10.1021/acsomega.0c05350.

Physicochemical characterization of NSVs the from sonication method, diameter kinetic profiles of NSV6grad and DOX-NSV6grad, mathematical models and fitting of NSV1grad in Hepes, mathematical models and fitting of NSV1grad in Serum/Hepes, mathematical models and fitting of NSV6grad in Hepes, mathematical models and fitting of NSV6grad in Serum/Hepes, MCF7 represents the cell viability upon incubation with different concentrations of empty NSVlgrad and NSV6grad and MDA MB 468 cell viability upon incubation with different concentrations of empty NSV1grad and NSV6grad, confocal microscopy analysis of rhodamine-DHPE NSV1grad at 6 and $24 \mathrm{~h}$ after post incubation with MCF-7 and MDA MB 468 cells, Z-stack of rhodamine-DHPE NSV1grad and rhodamine-DHPE NSV6grad after $24 \mathrm{~h}$ of incubation with MCF-7 and 
MDA MB 468 cells, chromatograms of DOX obtained after HPLC analysis, mathematical models and fitting of DOX-NSV1grad and DOX-NSV6grad in Hepes or Hepes/Serum using Weibull model, and statistical analysis of cytotoxic activity of DOX, DOX-NSV1grad, and DOX-NSV6grad on MCF7 and MDA MB 468 cell lines (PDF)

\section{AUTHOR INFORMATION}

\section{Corresponding Authors}

Luisa Di Marzio - Department of Pharmacy, University of Chieti-Pescara "G. d'Annunzio", 66100 Chieti, Italy; ○ orcid.org/0000-0002-2518-7188; Phone: +39 0871355 4705; Email: luisa.dimarzio@unich.it

Massimo Fresta - Department of Health Sciences, University of Catanzaro "Magna Graecia", 88100 Catanzaro, Italy; ๑ orcid.org/0000-0001-8062-817X; Phone: +39 0961369 4118; Email: fresta@unicz.it

\section{Authors}

Martina Di Francesco - Department of Health Sciences, University of Catanzaro "Magna Graecia", 88100 Catanzaro, Italy; Laboratory of Nanotechnology for Precision Medicine, Fondazione Istituto Italiano di Tecnologia, 16163 Genoa, Italy

Christian Celia - Department of Pharmacy, University of Chieti-Pescara "G. d'Annunzio", 66100 Chieti, Italy; (1) orcid.org/0000-0002-0590-5429

Maria Chiara Cristiano - Department of Clinical and Experimental Medicine, University of Catanzaro "Magna Graecia", 88100 Catanzaro, Italy

Nicola d'Avanzo - Department of Health Sciences, University of Catanzaro "Magna Graecia", 88100 Catanzaro, Italy; Department of Pharmacy, University of Chieti-Pescara " $G$. d'Annunzio", 66100 Chieti, Italy; 10 orcid.org/0000-00016945-6653

Barbara Ruozi - Department of Life Sciences, University of Modena and Reggio Emilia, I-41100 Modena, Italy; (1) orcid.org/0000-0002-2400-9910

Constantin Mircioiu - Department of Applied Mathematics and Biostatistics, Faculty of Pharmacy, "Carol Davila" University of Medicine and Pharmacy, 020956 Bucharest, Romania

Donato Cosco - Department of Health Sciences, University of Catanzaro "Magna Graecia", 88100 Catanzaro, Italy; () orcid.org/0000-0002-4898-0365

Complete contact information is available at:

https://pubs.acs.org/10.1021/acsomega.0c05350

\section{Author Contributions}

$\square_{\text {M.D.F. and C.C. contributed equally. }}$

\section{Author Contributions}

M.D.F. and C.C. contributed equally. M.D.F. synthesized, physicochemically characterized NSVs, performed data analyses, and drafted the manuscript. M.C.C. performed release study simulation and mathematical models and discussed data. N.D. performed Turbiscan analysis, analyzed, and discussed data. B.R. performed TEM analysis. M.C.C. and D.C. performed in vitro experiments and confocal analysis. L.D.M., C.C., and M.F. designed and supervised the project, analyzed, drafted the manuscript with the contribution of all the authors, revised, and approved the final draft before submission.

\section{Notes}

The authors declare no competing financial interest.

\section{ACKNOWLEDGMENTS}

The paper was supported by PRIN2017, Prot. no. 20173ZECCM 003/Italian Ministry of University and Research (D.C.); FAR 2018-2019, MIUR grant, University of Chieti-Pescara "G. d'Annunzio", Chieti, Italy, and FFARB 2017, Fondo per il Finanziamento delle Attività di Base di Ricerca MIUR grant (C.C. and L.D.M.). Research activity of M.C.C. was supported and co-founded by the European Commission, FESR FSE 2014-2020 and the final sponsorship of Calabria Region. These authors are grateful to Dr. Renato C. Barbacane for the language revision of the manuscript.

\section{REFERENCES}

(1) Bray, F.; Ferlay, J.; Soerjomataram, I.; Siegel, R. L.; Torre, L. A.; Jemal, A. Global cancer statistics 2018: GLOBOCAN estimates of incidence and mortality worldwide for 36 cancers in 185 countries. Ca-Cancer J. Clin. 2018, 68, 394-424.

(2) Hu, K.; Ding, P.; Wu, Y.; Tian, W.; Pan, T.; Zhang, S. Global patterns and trends in the breast cancer incidence and mortality according to sociodemographic indices: an observational study based on the global burden of diseases. BMJ open 2019, 9, e028461.

(3) Siegel, R. L.; Miller, K. D.; Jemal, A. Cancer statistics, 2020. CaCancer J. Clin. 2020, 70, 7-30.

(4) Galli, G.; Meda, F. From shared to dual leadership: a systematic literature review and an empirical analysis about how to lead innovation in two. Master Thesis, Milan Politecnico, 2019.

(5) Coelho, S. C.; Pereira, M. C.; Juzeniene, A.; Juzenas, P.; Coelho, M. A. N. Supramolecular nanoscale assemblies for cancer diagnosis and therapy. J. Controlled Release 2015, 213, 152-167.

(6) Hernandez-Aya, L. F.; Gonzalez-Angulo, A. M. Adjuvant systemic therapies in breast cancer. Surg. Clin. North Am. 2013, 93, 473-491.

(7) Li, Z.; Qiu, Y.; Lu, W.; Jiang, Y.; Wang, J. Immunotherapeutic interventions of Triple Negative Breast Cancer. J. Transl. Med. 2018, $16,147$.

(8) Sun, T.; Zhang, Y. S.; Pang, B.; Hyun, D. C.; Yang, M.; Xia, Y. Engineered nanoparticles for drug delivery in cancer therapy. Angew. Chem., Int. Ed. 2014, 53, 12320.

(9) Hafner, A.; Lovrić, J.; Lakoš, G. P.; Pepić, I. Nanotherapeutics in the EU: an overview on current state and future directions. Int. J. Nanomed. 2014, 9, 1005

(10) Grimaldi, N.; Andrade, F.; Segovia, N.; Ferrer-Tasies, L.; Sala, S.; Veciana, J.; Ventosa, N. Lipid-based nanovesicles for nanomedicine. Chem. Soc. Rev. 2016, 45, 6520-6545.

(11) Caster, J. M.; Patel, A. N.; Zhang, T.; Wang, A. Investigational nanomedicines in 2016: a review of nanotherapeutics currently undergoing clinical trials. Wiley Interdiscip. Rev.: Nanomed. Nanobiotechnol. 2017, 9, e1416.

(12) van der Meel, R.; Sulheim, E.; Shi, Y.; Kiessling, F.; Mulder, W. J. M.; Lammers, T. Smart cancer nanomedicine. Nat. Nanotechnol. 2019, 14, 1007-1017.

(13) Petros, R. A.; DeSimone, J. M. Strategies in the design of nanoparticles for therapeutic applications. Nat. Rev. Drug Discovery 2010, 9, 615-627.

(14) Di Francesco, V.; Gurgone, D.; Palomba, R.; Ferreira, M. F. M. M.; Catelani, T.; Cervadoro, A.; Maffia, P.; Decuzzi, P. Modulating Lipoprotein Transcellular Transport and Atherosclerotic Plaque Formation in $\mathrm{ApoE}^{-/-}$Mice via Nanoformulated Lipid-Methotrexate Conjugates. ACS Appl. Mater. Interfaces 2020, 12, 37943-37956.

(15) Bangham, A. D.; Standish, M. M.; Watkins, J. C. Diffusion of univalent ions across the lamellae of swollen phospholipids. J. Mol. Biol. 1965, 13, 238. 
(16) Allen, T. M.; Cullis, P. R. Liposomal drug delivery systems: from concept to clinical applications. Adv. Drug Deliv. Rev. 2013, 65, $36-48$.

(17) Bulbake, U.; Doppalapudi, S.; Kommineni, N.; Khan, W. Liposomal formulations in clinical use: an updated review. Pharmaceutics 2017, 9, 12.

(18) Beltrán-Gracia, E.; López-Camacho, A.; Higuera-Ciapara, I.; Velázquez-Fernández, J. B.; Vallejo-Cardona, A. A. Nanomedicine review: clinical developments in liposomal applications. Cancer Nanotechnol. 2019, 10, 11.

(19) Barenholz, Y. Doxil-the first FDA-approved nano-drug: lessons learned. J. Controlled Release 2012, 160, 117-134.

(20) Franco, Y.; Vaidya, T.; Ait-Oudhia, S. Anticancer and cardioprotective effects of liposomal doxorubicin in the treatment of breast cancer. Breast Canc. 2018, 10, 131.

(21) Torchilin, V. P. Recent advances with liposomes as pharmaceutical carriers. Nat. Rev. Drug Discovery 2005, 4, 145-160.

(22) Aggarwal, P.; Hall, J. B.; McLeland, C. B.; Dobrovolskaia, M. A.; McNeil, S. E. Nanoparticle interaction with plasma proteins as it relates to particle biodistribution, biocompatibility and therapeutic efficacy. Adv. Drug Deliv. Rev. 2009, 61, 428-437.

(23) Wu, N. Z.; Da, D.; Rudoll, T. L.; Needham, D.; Whorton, A. R.; Dewhirst, M. W. Increased microvascular permeability contributes to preferential accumulation of Stealth liposomes in tumor tissue. Cancer Res. 1993, 53, 3765.

(24) Pasut, G.; Paolino, D.; Celia, C.; Mero, A.; Joseph, A. S.; Wolfram, J.; Cosco, D.; Schiavon, O.; Shen, H.; Fresta, M. Polyethylene glycol (PEG)-dendron phospholipids as innovative constructs for the preparation of super stealth liposomes for anticancer therapy. J. Controlled Release 2015, 199, 106-113.

(25) Pannuzzo, M.; Esposito, S.; Wu, L.-P.; Key, J.; Aryal, S.; Celia, C.; di Marzio, L.; Moghimi, S. M.; Decuzzi, P. Overcoming Nanoparticle-Mediated Complement Activation by Surface PEGPairing. Nano Lett. 2020, 20, 4312-4321.

(26) Mare, R.; Paolino, D.; Celia, C.; Molinaro, R.; Fresta, M.; Cosco, D. Post-insertion parameters of PEG-derivatives in phosphocholine-liposomes. Int. J. Pharm. 2018, 552, 414-421.

(27) Kreuter, J.; Hekmatara, T.; Dreis, S.; Vogel, T.; Gelperina, S.; Langer, K. Covalent attachment of apolipoprotein AI and apolipoprotein B-100 to albumin nanoparticles enables drug transport into the brain. J. Controlled Release 2007, 118, 54-58.

(28) Paolino, D.; Accolla, M. L.; Cilurzo, F.; Cristiano, M. C.; Cosco, D.; Castelli, F.; Sarpietro, M. G.; Fresta, M.; Celia, C. Interaction between PEG lipid and DSPE/DSPC phospholipids: an insight of PEGylation degree and kinetics of de-PEGylation. Colloids Surf., B 2017, 155, 266-275.

(29) Knop, K.; Hoogenboom, R.; Fischer, D.; Schubert, U. S. Poly (ethylene glycol) in drug delivery: pros and cons as well as potential alternatives. Angew. Chem., Int. Ed. 2010, 49, 6288-6308.

(30) Nowroozi, F.; Dadashzadeh, S.; Soleimanjahi, H.; Haeri, A.; Shahhosseini, S.; Javidi, J.; Karimi, H. Theranostic niosomes for direct intratumoral injection: marked enhancement in tumor retention and anticancer efficacy. Nanomedicine 2018, 13, 2201-2219.

(31) Marianecci, C.; Di Marzio, L.; Rinaldi, F.; Celia, C.; Paolino, D.; Alhaique, F.; Esposito, S.; Carafa, M. Niosomes from 80s to present: the state of the art. Adv. Colloid Interface Sci. 2014, 205, 187206.

(32) Marianecci, C.; Rinaldi, F.; Di Marzio, L.; Mastriota, M.; Pieretti, S.; Celia, C.; Paolino, D.; Iannone, M.; Fresta, M.; Carafa, M. Ammonium glycyrrhizinate-loaded niosomes as a potential nanotherapeutic system for anti-inflammatory activity in murine models. Int. J. Nanomed. 2014, 9, 635.

(33) Marianecci, C.; Paolino, D.; Celia, C.; Fresta, M.; Carafa, M.; Alhaique, F. Non-ionic surfactant vesicles in pulmonary glucocorticoid delivery: characterization and interaction with human lung fibroblasts. J. Controlled Release 2010, 147, 127-135.

(34) Sajjadi, S.; Zerfa, M.; Brooks, B. W. Phase inversion in pxylene/water emulsions with the non-ionic surfactant pair sorbitan monolaurate/polyoxyethylene sorbitan monolaurate (Span 20/Tween 20). Colloids Surf., A 2003, 218, 241-254.

(35) Slamon, D. J.; Leyland-Jones, B.; Shak, S.; Fuchs, H.; Paton, V.; Bajamonde, A.; Fleming, T.; Eiermann, W.; Wolter, J.; Pegram, M.; Baselga, J.; Norton, L. Use of chemotherapy plus a monoclonal antibody against HER2 for metastatic breast cancer that overexpresses HER2. N. Engl. J. Med. 2001, 344, 783-792.

(36) Ansari, L.; Shiehzadeh, F.; Taherzadeh, Z.; Nikoofal-Sahlabadi, S.; Momtazi-Borojeni, A. A.; Sahebkar, A.; Eslami, S. The most prevalent side effects of pegylated liposomal doxorubicin monotherapy in women with metastatic breast cancer: a systematic review of clinical trials. Cancer Gene Ther. 2017, 24, 189-193.

(37) Ogawara, K.-i.; Un, K.; Tanaka, K.-i.; Higaki, K.; Kimura, T. In vivo anti-tumor effect of PEG liposomal doxorubicin (DOX) in DOXresistant tumor-bearing mice: Involvement of cytotoxic effect on vascular endothelial cells. J. Controlled Release 2009, 133, 4-10.

(38) Mayer, L. D.; Tai, L. C.; Ko, D. S.; Masin, D.; Ginsberg, R. S.; Cullis, P. R.; Bally, M. B. Influence of vesicle size, lipid composition, and drug-to-lipid ratio on the biological activity of liposomal doxorubicin in mice. Cancer Res. 1989, 49, 5922.

(39) Holliday, D. L.; Speirs, V. Choosing the right cell line for breast cancer research. Breast Cancer Res. 2011, 13, 215.

(40) Moghimi, S. M.; Hunter, A. C.; Murray, J. C. Nanomedicine: current status and future prospects. FASEB J. 2005, 19, 311-330.

(41) Mullis, A. S.; Broderick, S. R.; Binnebose, A. M.; PeroutkaBigus, N.; Bellaire, B. H.; Rajan, K.; Narasimhan, B. Data Analytics Approach for Rational Design of Nanomedicines with Programmable Drug Release. Mol. Pharm. 2019, 16, 1917-1928.

(42) Tavano, L.; Vivacqua, M.; Carito, V.; Muzzalupo, R.; Caroleo, M. C.; Nicoletta, F. Doxorubicin loaded magneto-niosomes for targeted drug delivery. Colloids Surf., B 2013, 102, 803-807.

(43) Manconi, M.; Sinico, C.; Valenti, D.; Loy, G.; Fadda, A. M. Niosomes as carriers for tretinoin. I. Preparation and properties. Int. J. Pharm. 2002, 234, 237-248.

(44) Di Francesco, M.; Celia, C.; Primavera, R.; D’Avanzo, N.; Locatelli, M.; Fresta, M.; Cilurzo, F.; Ventura, C. A.; Paolino, D.; Di Marzio, L. Physicochemical characterization of $\mathrm{pH}$-responsive and fusogenic self-assembled non-phospholipid vesicles for a potential multiple targeting therapy. Int. J. Pharm. 2017, 528, 18-32.

(45) Cullis, P. R.; Mayer, L. D.; Bally, M. B.; Madden, T. D.; Hope, M. J. Generating and loading of liposomal systems for drug-delivery applications. Adv. Drug Deliv. Rev. 1989, 3, 267-282.

(46) Hashemi Dehaghi, M.; Haeri, A.; Keshvari, H.; Abbasian, Z.; Dadashzadeh, S. Dorzolamide loaded niosomal vesicles: comparison of passive and remote loading methods. Iran J. Pharm. Res. 2017, 16, 413.

(47) Zucker, D.; Marcus, D.; Barenholz, Y.; Goldblum, A. Liposome drugs' loading efficiency: a working model based on loading conditions and drug's physicochemical properties. J. Controlled Release 2009, 139, 73-80.

(48) Tamam, H.; Park, J.; Gadalla, H. H.; Masters, A. R.; AbdelAleem, J. A.; Abdelrahman, S. I.; Abdelrahman, A. A.; Lyle, L. T.; Yeo, Y. Development of liposomal gemcitabine with high drug loading capacity. Mol. Pharm. 2019, 16, 2858-2871.

(49) Primavera, R.; Di Francesco, M.; De Cola, A.; De Laurenzi, V.; Paolino, D.; Ciancaioni, M.; Carafa, M.; Celia, C.; Di Ilio, C.; Di Stefano, A.; Fresta, M.; Locatelli, M.; Di Marzio, L. HPLC-FLD and spectrofluorometer apparatus: How to best detect fluorescent probeloaded niosomes in biological samples. Colloids Surf., B 2015, 135, $575-580$.

(50) Naderinezhad, S.; Amoabediny, G.; Haghiralsadat, F. Codelivery of hydrophilic and hydrophobic anticancer drugs using biocompatible $\mathrm{pH}$-sensitive lipid-based nano-carriers for multidrugresistant cancers. RSC Adv. 2017, 7, 30008-30019.

(51) Hughes, G. A. Nanostructure-mediated drug delivery. Nanomedicine in Cancer; Pan Stanford, 2017; pp 47-72.

(52) Honary, S.; Zahir, F. Effect of zeta potential on the properties of nano-drug delivery systems-a review (Part 1). Trop. J. Pharm. Res. 2013, 12, 255-264. 
(53) Zare Kazemabadi, F.; Heydarinasab, A.; Akbarzadeh, A.; Ardjmand, M. Preparation, characterization and in vitro evaluation of PEGylated nanoliposomal containing etoposide on lung cancer. Artif. Cells, Nanomed., Biotechnol. 2019, 47, 3222-3230.

(54) Fritze, A.; Hens, F.; Kimpfler, A.; Schubert, R.; Peschka-Süss, R. Remote loading of doxorubicin into liposomes driven by a transmembrane phosphate gradient. Biochim. Biophys. Acta, Biomembr. 2006, 1758, 1633-1640.

(55) Calvagno, M. G.; Celia, C.; Paolino, D.; Cosco, D.; Iannone, M.; Castelli, F.; Doldo, P.; Frest, M. Effects of lipid composition and preparation conditions on physical-chemical properties, technological parameters and in vitro biological activity of gemcitabine-loaded liposomes. Curr. Drug Deliv. 2007, 4, 89-101.

(56) Maiti, S.; Paul, S.; Mondol, R.; Ray, S.; Sa, B. Nanovesicular formulation of brimonidine tartrate for the management of glaucoma: in vitro and in vivo evaluation. AAPS PharmSciTech 2011, 12, 755763.

(57) Guinedi, A. S.; Mortada, N. D.; Mansour, S.; Hathout, R. M. Preparation and evaluation of reverse-phase evaporation and multilamellar niosomes as ophthalmic carriers of acetazolamide. Int. J. Pharm. 2005, 306, 71-82.

(58) Fenske, D. B.; Cullis, P. R. Entrapment of small molecules and nucleic acid-based drugs in liposomes. In Methods in Enzymology; Elsevier, 2005; Vol. 391, pp 7-40.

(59) Uchegbu, I. F.; Vyas, S. P. Non-ionic surfactant based vesicles (niosomes) in drug delivery. Int. J. Pharm. 1998, 172, 33-70.

(60) Palange, A. L.; Di Mascolo, D.; Carallo, C.; Gnasso, A.; Decuzzi, P. Lipid-polymer nanoparticles encapsulating curcumin for modulating the vascular deposition of breast cancer cells. Nanomedicine 2014, 10, e991-e1002.

(61) Primavera, R.; Palumbo, P.; Celia, C.; Cilurzo, F.; Cinque, B.; Carata, E.; Carafa, M.; Paolino, D.; Cifone, M.; Di Marzio, L. Corrigendum to "An insight ofin vitrotransport of PEGylated nonionic surfactant vesicles (NSVs) across the intestinal polarized enterocyte monolayers"[Eur. J. Pharm. Biopharm. 127 (2018) 432442]. Eur. J. Pharm. Biopharm. 2018, 128, 128.

(62) Agarwal, R.; Katare, O. P.; Vyas, S. P. Preparation and in vitro evaluation of liposomal/niosomal delivery systems for antipsoriatic drug dithranol. Int. J. Pharm. 2001, 228, 43-52.

(63) Johnston, M. J. W.; Semple, S. C.; Klimuk, S. K.; Edwards, K.; Eisenhardt, M. L.; Leng, E. C.; Karlsson, G.; Yanko, D.; Cullis, P. R. Therapeutically optimized rates of drug release can be achieved by varying the drug-to-lipid ratio in liposomal vincristine formulations. Biochim. Biophys. Acta, Biomembr. 2006, 1758, 55-64.

(64) Cern, A.; Barenholz, Y.; Tropsha, A.; Goldblum, A. Computeraided design of liposomal drugs: in silico prediction and experimental validation of drug candidates for liposomal remote loading. $J$. Controlled Release 2014, 173, 125-131.

(65) Ferrari, M. Frontiers in cancer nanomedicine: directing mass transport through biological barriers. Trends Biotechnol. 2010, 28, $181-188$.

(66) Monopoli, M. P.; Åberg, C.; Salvati, A.; Dawson, K. A. Biomolecular coronas provide the biological identity of nanosized materials. Nat. Nanotechnol. 2012, 7, 779.

(67) Sabín, J.; Prieto, G.; Ruso, J. M.; Hidalgo-Alvarez, R.; Sarmiento, F. Size and stability of liposomes: a possible role of hydration and osmotic forces. Eur. Phys. J. E 2006, 20, 401.

(68) Wolfram, J.; Suri, K.; Yang, Y.; Shen, J.; Celia, C.; Fresta, M.; Zhao, Y.; Shen, H.; Ferrari, M. Shrinkage of pegylated and nonpegylated liposomes in serum. Colloids Surf., B 2014, 114, 294-300.

(69) Hioki, A.; Wakasugi, A.; Kawano, K.; Hattori, Y.; Maitani, Y. Development of an in vitro drug release assay of PEGylated liposome using bovine serum albumin and high temperature. Biol. Pharm. Bull. 2010, 33, 1466-1470.

(70) Hadjidemetriou, M.; Al-Ahmady, Z.; Mazza, M.; Collins, R. F.; Dawson, K.; Kostarelos, K. In vivo biomolecule corona around bloodcirculating, clinically used and antibody-targeted lipid bilayer nanoscale vesicles. ACS Nano 2015, 9, 8142-8156.
(71) Rinaldi, F.; del Favero, E.; Moeller, J.; Hanieh, P. N.; Passeri, D.; Rossi, M.; Angeloni, L.; Venditti, I.; Marianecci, C.; Carafa, M.; Fratoddi, I. Hydrophilic silver nanoparticles loaded into niosomes: Physical-chemical characterization in view of biological applications. Nanomaterials 2019, 9, 1177.

(72) Foteini, P.; Pippa, N.; Naziris, N.; Demetzos, C. Physicochemical study of the protein-liposome interactions: Influence of liposome composition and concentration on protein binding. J. Liposome Res. 2019, 29, 313-321.

(73) Pozzi, D.; Caracciolo, G.; Digiacomo, L.; Colapicchioni, V.; Palchetti, S.; Capriotti, A. L.; Cavaliere, C.; Zenezini Chiozzi, R.; Puglisi, A.; Laganà, A. The biomolecular corona of nanoparticles in circulating biological media. Nanoscale 2015, 7, 13958-13966.

(74) Palchetti, S.; Colapicchioni, V.; Digiacomo, L.; Caracciolo, G.; Pozzi, D.; Capriotti, A. L.; La Barbera, G.; Laganà, A. The protein corona of circulating PEGylated liposomes. Biochim. Biophys. Acta, Biomembr. 2016, 1858, 189-196.

(75) Celia, C.; Trapasso, E.; Cosco, D.; Paolino, D.; Fresta, M. Turbiscan Lab Expert analysis of the stability of ethosomes ${ }^{\circledR}$ and ultradeformable liposomes containing a bilayer fluidizing agent. Colloids Surf., B 2009, 72, 155-160.

(76) Di Francesco, M.; Primavera, R.; Fiorito, S.; Cristiano, M. C.; Taddeo, V. A.; Epifano, F.; Di Marzio, L.; Genovese, S.; Celia, C. Acronychiabaueri analogue derivative-loaded ultradeformable vesicles: physicochemical characterization and potential applications. Planta Med. 2017, 83, 482-491.

(77) Gagliardi, A.; Bonacci, S.; Paolino, D.; Celia, C.; Procopio, A.; Fresta, M.; Cosco, D. Paclitaxel-loaded sodium deoxycholatestabilized zein nanoparticles: characterization and in vitro cytotoxicity. Heliyon 2019, 5, e02422.

(78) Cristiano, M. C.; Froiio, F.; Spaccapelo, R.; Mancuso, A.; Nisticò, S. P.; Udongo, B. P.; Fresta, M.; Paolino, D. SulforaphaneLoaded Ultradeformable Vesicles as A Potential Natural Nanomedicine for the Treatment of Skin Cancer Diseases. Pharmaceutics 2020, 12,6 .

(79) Roque, L.; Fernández, M.; Benito, J. M.; Escudero, I. Stability and characterization studies of Span 80 niosomes modified with CTAB in the presence of $\mathrm{NaCl}$. Colloids Surf., A 2020, 601, 124999.

(80) Gao, J.-Q.; Lv, Q.; Li, L.-M.; Tang, X.-J.; Li, F.-Z.; Hu, Y.-L.; Han, M. Glioma targeting and blood-brain barrier penetration by dual-targeting doxorubincin liposomes. Biomaterials 2013, 34, 56285639.

(81) Sadeghi, N.; Deckers, R.; Ozbakir, B.; Akthar, S.; Kok, R. J.; Lammers, T.; Storm, G. Influence of cholesterol inclusion on the doxorubicin release characteristics of lysolipid-based thermosensitive liposomes. Int. J. Pharm. 2018, 548, 778-782.

(82) Suk, J. S.; Xu, Q.; Kim, N.; Hanes, J.; Ensign, L. M. PEGylation as a strategy for improving nanoparticle-based drug and gene delivery. Adv. Drug Deliv. Rev. 2016, 99, 28-51.

(83) Immordino, M. L.; Dosio, F.; Cattel, L. Stealth liposomes: review of the basic science, rationale, and clinical applications, existing and potential. Int. J. Nanomed. 2006, 1, 297.

(84) Nag, O.; Awasthi, V. Surface engineering of liposomes for stealth behavior. Pharmaceutics 2013, 5, 542-569.

(85) Cipolla, D.; Wu, H.; Eastman, S.; Redelmeier, T.; Gonda, I.; Chan, H. K. Development and characterization of an in vitro release assay for liposomal ciprofloxacin for inhalation. J. Pharm. Sci. 2014, 103, 314-327.

(86) Wei, J.; Ravn, D. B.; Gram, L.; Kingshott, P. Stainless steel modified with poly (ethylene glycol) can prevent protein adsorption but not bacterial adhesion. Colloids Surf., B 2003, 32, 275-291.

(87) Gabizon, A.; Tzemach, D.; Mak, L.; Bronstein, M.; Horowitz, A. T. Dose dependency of pharmacokinetics and therapeutic efficacy of pegylated liposomal doxorubicin (DOXIL) in murine models. $J$. Drug Target. 2002, 10, 539-548.

(88) Mircioiu, C.; Voicu, V.; Anuta, V.; Tudose, A.; Celia, C.; Paolino, D.; Fresta, M.; Sandulovici, R.; Mircioiu, I. Mathematical modeling of release kinetics from supramolecular drug delivery systems. Pharmaceutics 2019, 11, 140. 
(89) Paolino, D.; Tudose, A.; Celia, C.; Di Marzio, L.; Cilurzo, F.; Mircioiu, C. Mathematical Models as Tools to Predict the Release Kinetic of Fluorescein from Lyotropic Colloidal Liquid Crystals. Materials 2019, 12, 693.

(90) Ruckmani, K.; Sankar, V. Formulation and optimization of zidovudine niosomes. AAPS PharmSciTech 2010, 11, 1119-1127.

(91) Papadopoulou, V.; Kosmidis, K.; Vlachou, M.; Macheras, P. On the use of the Weibull function for the discernment of drug release mechanisms. Int. J. Pharm. 2006, 309, 44-50.

(92) Russell, L. M.; Hultz, M.; Searson, P. C. Leakage kinetics of the liposomal chemotherapeutic agent Doxil: The role of dissolution, protonation, and passive transport, and implications for mechanism of action. J. Controlled Release 2018, 269, 171-176.

(93) Fröhlich, E. The role of surface charge in cellular uptake and cytotoxicity of medical nanoparticles. Int. J. Nanomed. 2012, 7, 5577.

(94) Allen, T. M.; Austin, G. A.; Chonn, A.; Lin, L.; Lee, K. C. Uptake of liposomes by cultured mouse bone marrow macrophages: influence of liposome composition and size. Biochim. Biophys. Acta, Biomembr. 1991, 1061, 56-64.

(95) Allen, T. M.; Williamson, P.; Schlegel, R. A. Phosphatidylserine as a determinant of reticuloendothelial recognition of liposome models of the erythrocyte surface. Proc. Natl. Acad. Sci. U.S.A. 1988, 85, 8067-8071.

(96) Fang, Y.; Xue, J.; Gao, S.; Lu, A.; Yang, D.; Jiang, H.; He, Y.; Shi, K. Cleavable PEGylation: a strategy for overcoming the "PEG dilemma" in efficient drug delivery. Drug Deliv. 2017, 24, 22-32.

(97) Azizi, E.; Namazi, A.; Kaabinejadian, S.; Fouladdel, S.; Rezaei, P.; Ramezani, M. Molecular analysis of MEN1 expression in MCF7, T47D and MDA-MB 468 breast cancer cell lines treated with adriamycin using RT-PCR and immunocytochemistry. Daru, J. Pharm. Sci. 2010, 18, 17.

(98) Wen, S.-h.; Su, S.-c.; Liou, B.-h.; Lin, C.-h.; Lee, K.-r. Sulbactam-enhanced cytotoxicity of doxorubicin in breast cancer cells. Cancer Cell Int. 2018, 18, 128.

(99) Pramanik, D.; Campbell, N. R.; Das, S.; Gupta, S.; Chenna, V.; Bisht, S.; Sysa-Shah, P.; Bedja, D.; Karikari, C.; Steenbergen, C.; Gabrielson, K. L.; Maitra, A.; Maitra, A. A composite polymer nanoparticle overcomes multidrug resistance and ameliorates doxorubicin-associated cardiomyopathy. Oncotarget 2012, 3, 640.

(100) De Rose, R.; Cristiano, M.; Celano, M.; Maggisano, V.; Vero, A.; Lombardo, G.; Di Francesco, M.; Paolino, D.; Russo, D.; Cosco, D. PDE5 inhibitors-loaded nanovesicles: Physico-chemical properties and in vitro antiproliferative activity. Nanomaterials 2016, 6, 92.

(101) Gandhi, R.; Khatri, N.; Baradia, D.; Vhora, I.; Misra, A. Surface-modified Epirubicin- $\mathrm{HCl}$ liposomes and its in vitro assessment in breast cancer cell-line: MCF-7. Drug Deliv. 2016, 23, 11521162.

(102) Song, L.; Falzone, N.; Vallis, K. A. EGF-coated gold nanoparticles provide an efficient nano-scale delivery system for the molecular radiotherapy of EGFR-positive cancer. Int. J. Radiat. Biol. 2016, 92, 716-723.

(103) Ruozi, B.; Belletti, D.; Tombesi, A.; Tosi, G.; Bondioli, L.; Forni, F.; Maria Angela Vandelli, M. A. AFM, ESEM, TEM, and CLSM in liposomal characterization: a comparative study. Int. J. Nanomed. 2011, 6, 557.

(104) Charrois, G. J. R.; Allen, T. M. Drug release rate influences the pharmacokinetics, biodistribution, therapeutic activity, and toxicity of pegylated liposomal doxorubicin formulations in murine breast cancer. Biochim. Biophys. Acta, Biomembr. 2004, 1663, 167-177. 